\title{
Deformation and fracture of impulsively loaded sandwich panels
}

\author{
H.N.G. Wadley ${ }^{\text {a,*, }}$ T. Børvik ${ }^{\text {b,c }}$, L. Olovsson ${ }^{\text {d }}$, J.J. Wetzel $^{\text {a }}$, K.P. Dharmasena ${ }^{\text {a }}$, \\ O.S. Hopperstad ${ }^{\text {b }}$, V.S. Deshpande ${ }^{\mathrm{e}}$, J.W. Hutchinson ${ }^{\mathrm{f}}$
}

a Department of Materials Science and Engineering, University of Virginia, Charlottesville, VA 22904, USA

b Structural Impact Laboratory (SIMLab), Centre for Research-based Innovation (CRI) and Department of Structural Engineering, Norwegian University of Science and Technology, Rich. Birkelands vei 1A, NO-7491 Trondheim, Norway

${ }^{\mathrm{c}}$ Norwegian Defense Estates Agency, Research \& Development Department, PB 405, Sentrum, NO-0103 Oslo, Norway

¿ IMPETUS Afea AB, Sördalavägen 22, SE-141 60 Huddinge, Sweden

e Department of Engineering, University of Cambridge, Trumpington Street, Cambridge CB2 1PZ, UK

${ }^{\mathrm{f}}$ School of Engineering and Applied Science, Harvard University, Cambridge, MA, USA

\section{A R T I C L E I N F O}

\section{Article history:}

Received 26 October 2011

Received in revised form

19 July 2012

Accepted 22 July 2012

Available online 8 August 2012

\section{Keywords:}

Blast loading

Aluminum sandwich panels

Friction stir welding

HAZ

Discrete particle method

Finite element simulation

\begin{abstract}
A B S T R A C T
Light metal sandwich panel structures with cellular cores have attracted interest for multifunctional applications which exploit their high bend strength and impact energy absorption. This concept has been explored here using a model 6061-T6 aluminum alloy system fabricated by friction stir weld joining extruded sandwich panels with a triangular corrugated core. Micro-hardness and miniature tensile coupon testing revealed that friction stir welding reduced the strength and ductility in the welds and a narrow heat affected zone on either side of the weld by approximately $30 \%$. Square, edge clamped sandwich panels and solid plates of equal mass per unit area were subjected to localized impulsive loading by the impact of explosively accelerated, water saturated, sand shells. The hydrodynamic load and impulse applied by the sand were gradually increased by reducing the stand-off distance between the test charge and panel surfaces. The sandwich panels suffered global bending and stretching, and localized core crushing. As the pressure applied by the sand increased, face sheet fracture by a combination of tensile stretching and shear-off occurred first at the two clamped edges of the panels that were parallel with the corrugation and weld direction. The plane of these fractures always lay within the heat affected zone of the longitudinal welds. For the most intensively loaded panels additional cracks occurred at the other clamped boundaries and in the center of the panel. To investigate the dynamic deformation and fracture processes, a particle-based method has been used to simulate the impulsive loading of the panels. This has been combined with a finite element analysis utilizing a modified Johnson-Cook constitutive relation and a CockcroftLatham fracture criterion that accounted for local variation in material properties. The fully coupled simulation approach enabled the relationships between the soilexplosive test charge design, panel geometry, spatially varying material properties and the panel's deformation and dynamic failure responses to be explored. This comprehensive study reveals the existence of a strong instability in the loading that results from changes in sand particle reflection during dynamic evolution of the panel's surface topology. Significant fluid-structure interaction effects are also discovered at the sample sides and corners due to changes of the sand reflection angle by the edge clamping system.
\end{abstract}

(c) 2012 Elsevier Ltd. All rights reserved.

\footnotetext{
* Corresponding author. Tel.: +1 4349825671.

E-mail address: haydn@virginia.edu (H.N.G. Wadley).
} 


\section{Introduction}

Sandwich panel structures constructed from light, stiff, strong face sheets separated by low density cores are highly efficient at supporting bending loads and widely used in weight sensitive applications (Allen, 1969). Because some highly porous (cellular) core materials also have high specific mechanical energy absorption, they have also been used for impact mitigation (Gibson and Ashby, 1997; Mills, 2007). For instance, metallic sandwich panels made from corrosion resistant stainless steel alloys with prismatic, honeycomb and lattice truss topology cores have attracted significant recent interest for mitigating the transmitted pressure and impulse during interactions with shock fronts in air and underwater (Dharmasena et al., 2008; Wei et al., 2008; Fleck and Deshpande, 2004; Hutchinson and Xue, 2005). The use of sandwich panels for shock load mitigation in water exploit both a fluid-structure interaction (FSI) effect between fluid transported shock fronts and the impacted face sheet and the high bending resistance of sandwich panels (Xue and Hutchinson, 2004; Liang et al., 2007; Vaziri and Hutchinson, 2007). A beneficial FSI arises when a light (low inertia) plate is impacted by a fluid transported impulse. Taylor (1963) showed that in water, the reflected impulse (and therefore that transmitted into the plate) could be reduced if the plate was able to move away from the impulse during the interaction. Sandwich panels with light faces and weak cores (compared to the shock over-pressure) are able to achieve this condition, and significant impulse reductions have been predicted (Hutchinson and Xue, 2005; Tilbrook et al., 2006; Liang et al., 2007) and experimentally observed (Dharmasena et al., 2009, 2010) during underwater loading.

Recent theoretical (Vaziri and Hutchinson, 2007) and numerical assessments (Kambouchev et al., 2006, 2007) indicate that non-linear compressibility effects in air result in smaller, but still significant, FSI effects provided the shock overpressure is high and the face sheets have a sufficiently low mass per unit area. Recent experiments have shown that sandwich panels with thin face sheets and weak, pyramidal lattice cores suffer up to 30\% smaller back face deflections than monolithic plates with the same mass per unit area (i.e. areal density) when shock loaded in air (Dharmasena et al., 2011). However, as the face sheet thickness was reduced in these experiments (to more effectively utilize FSI effects), they eventually suffered rupture at the nodes where the (inertia stabilized) core trusses were bonded to the face sheet. Experiments with much higher intensity (more non-linear) shocks have shown similar deflection improvements when strong honeycomb cores were combined with thick face sheets made from high ductility stainless steels (Dharmasena et al., 2008). These experiments indicated that both the FSI effect and the panels bending resistance can contribute to reduced panel's deflections even in air loading situations.

The use of light metallic alloys for sandwich panel construction offers a potential means for reducing the mass per unit area of a shock impacted face sheet (and therefore enhancing the FSI effect) without reducing its thickness. Several methods have been proposed for sandwich panel fabrication using titanium (Queheillalt et al., 2000; Elzey and Wadley, 2001; Moongkhamklang and Wadley, 2010; Queheillalt and Wadley, 2009) and other materials (Wadley, 2008). One approach well suited to the fabrication of low relative open cell cores with lattice truss topologies utilizes brazing methods to attach the core to the face sheets (Kooistra et al., 2004, 2008). However, the lower ductility of these nodes can lead to early failure under in-plane shear loading. These open cell core structures also provide little resistance to in-plane stretching during the large scale panel bending that can accompany high intensity loading. Recently, extrusion based approaches for making sandwich panels with integrally bonded triangular corrugated cores have emerged (Queheillalt et al., 2008; Børvik et al., 2008a,b). These panels have nodes made of the same alloy used for the faces and core, and are therefore of similar strength and ductility to other parts of the structure. The corrugated webs are also stretch resistant in the longitudinal (extrusion) direction.

The detonation of an explosive buried in soil can impulsively load a structure by a combination of soil particle impact and air transmitted impulse (Deshpande et al., 2009). However, efforts to model and simulate the interaction are complicated by the difficulty of accurately representing the constitutive properties of the soil and its interaction with a deformable structure. Various continuum approaches have been reported including those based upon an arbitrary coupling of Euler and Lagrangian methods (ALE) (Børvik et al., 2009), but these approaches remain challenging. Rimoli et al. (2011) have recently used a decoupled approach to analyze the impact of wet sand with an extruded corrugated core aluminum sandwich structure. In this approach a constitutive model for wet sand (Deshpande et al., 2009) was used to deduce a pressure profile that was applied to a plate and its deformation was then predicted with finite element methods. While general trends were captured by this approach, it failed to address the soil's coupled interaction with the dynamically deforming panel which is essential to understand FSI effects; it also utilized a generic model for the constitutive response of the aluminum alloy, and it did not address panel fracture which became significant under intense loading.

Here, we briefly summarize the experiments performed by Rimoli et al. (2011), and characterize the fracture processes activated by impulsive loading. The square panels used in these experiments were fabricated from narrow extruded aluminum alloy sandwich panels that were joined by friction stir welding in the longitudinal (extrusion) direction. They were impulsively loaded by an explosively accelerated, spherical shell of water saturated synthetic sand (glass microspheres) and their deformation and fracture modes compared to those of a monolithic plate of the same alloy with identical mass per unit area (areal density). The experiments revealed that sandwich panel structures suffer smaller deflections than equivalent solid structures at low impulses levels, but are more susceptible to fracture in the most severely loaded scenarios. We then present a fully coupled simulation approach that permits a detailed investigation of FSI effects and fracture mechanisms induced by these experiments. The simulation approach is based upon a recently 
developed particle-based method which couples the interaction of the explosion with the sand particles and simulates their subsequent interaction with a test structure. Using robust finite element methods, we simulate the structure's dynamic response and predict the dynamic deflections, deformation mechanisms and fracture modes of the sandwich panels. The model incorporates a modified Johnson-Cook constitutive relation for the aluminum alloy. The CockcroftLatham failure criterion is used to describe the dynamic fracture processes that lead to panel failure in the most intensely loaded test scenarios. The models take into account the measured reductions in strength and ductility of the friction stir weld and heat affected zone (HAZ) at the longitudinal connections between the extrusions. The study reveals good agreement between the experimentally observed deformation/fracture phenomena and that simulated, and therefore validates the discrete particle-based method for aluminum panels that fail during impulse loading. A key finding of the work is the discovery of a strong coupling between the dynamically evolving surface of the impacted structure and the local transmitted impulse intensity. This can lead to instabilities and premature failure of test structures at regions of enhanced soil particle reflection.

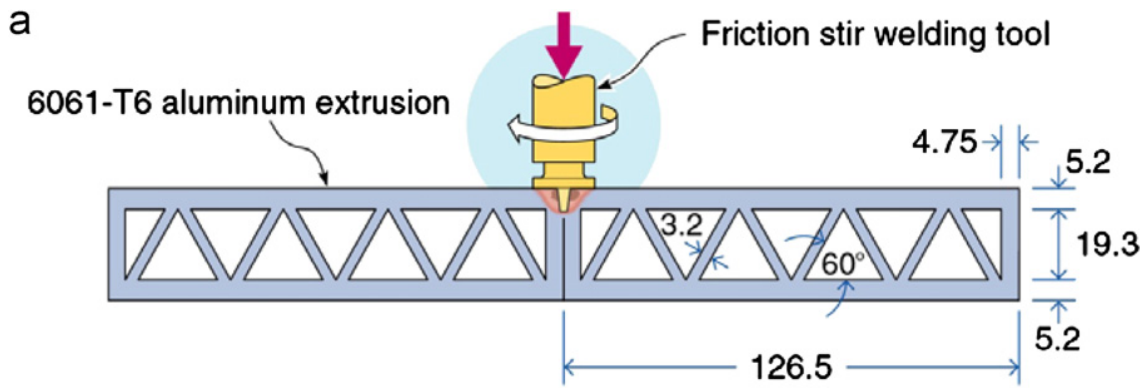

b

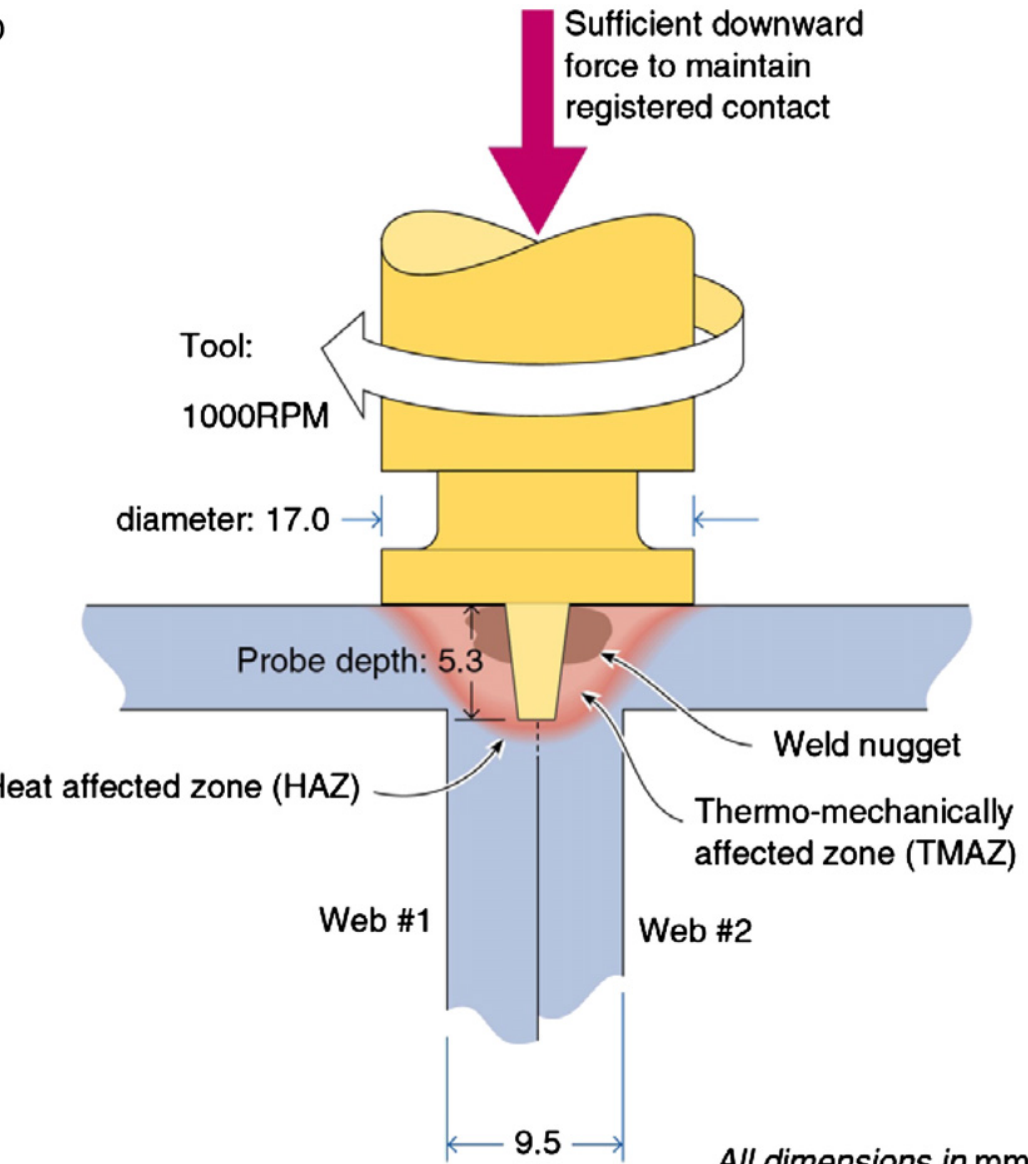

Fig. 1. Schematic illustration of the friction stir welding process used to fabricate sandwich panels from 126 mm wide 6061 -T6 aluminum alloy extruded sandwich panel sections with a corrugated core. (a) Linear friction stir welding and (b) closeup detail. 


\section{Experimental study}

\subsection{Panel design and fabrication}

Sandwich panels for edge clamped experimental testing were made by friction stir weld joining five 141.5 mm wide, 6061-T6 aluminum alloy extrusions with a corrugated core design (Fig. 1). The aluminum alloy extrusions were fabricated by a porthole extrusion process using a 300 ton direct extrusion press operating at $482{ }^{\circ} \mathrm{C}$ (Rimoli et al., 2011). The extruded structures had a corrugation web thickness of $3.2 \mathrm{~mm}$, a core height of $19.3 \mathrm{~mm} ; 5.2 \mathrm{~mm}$ thick face sheets and a web inclination angle of $60^{\circ}$. After heat treating to the T6 condition, the sides of the extrusions were machined to leave $4.75 \mathrm{~mm}$ wide vertical webs and then cut to $610 \mathrm{~mm}$ lengths. The five extruded panels were then butted together and friction stir welded in the longitudinal (extrusion and corrugation) direction using a $15 \mathrm{~mm}$ diameter welding tool turning at 1000 revolutions per minute to create square test panels. The core of the panels consisted of five identical super cells each consisting of four triangular corrugations separated by $9.5 \mathrm{~mm}$ wide vertical webs positioned beneath each of the welds. These vertical webs were intended to provide load support during friction stir welding as well as local reinforcement of the core to reduce the likelihood of face sheet failure in the welded regions. The relative density of this hybrid (vertical and inclined web) topology core was $29 \%$. The core crush strength was $58 \mathrm{MPa}$ and the in-plane shear yield strength (measured transverse to the corrugations) was $24 \mathrm{MPa}$ (Wetzel, 2009). The areal density of the sandwich panel (the core and two faces) was $46 \mathrm{~kg} / \mathrm{m}^{2}$.

\subsection{Material tests and characterization}

The hot $\left(482^{\circ} \mathrm{C}\right)$ extrusion process used to fabricate the sandwich panel structures separated the alloy billet into several pieces, severely deformed each of them and then rejoined the metal streams to create the final structure. The panels were then rapidly cooled and subjected to a T6 heat treatment that resulted in a final strength in the $300 \mathrm{MPa}$ range. The measured micro-hardness lay in the range $102 \pm 5 \mathrm{HVN}$ which also corresponded to an alloy tensile strength of about $300 \pm 15 \mathrm{MPa}$. However, the inhomogeneous metal deformation processes resulted in a spatially varying grain structure in the cross-section of the panels as shown in Fig. 2. The surface grains were larger than those in the interior of the panel and were elongated in the extrusion direction.

The complex grain structure in the surface of a face sheet that included a friction stir weld is shown in Fig. 3 . The grains within the friction stir weld were too fine to resolve in the photograph. Severe grain distortion was evident in the face sheet on either side of the weld. Fig. 4 shows a micro-hardness profile (converted to equivalent ultimate tensile strength)

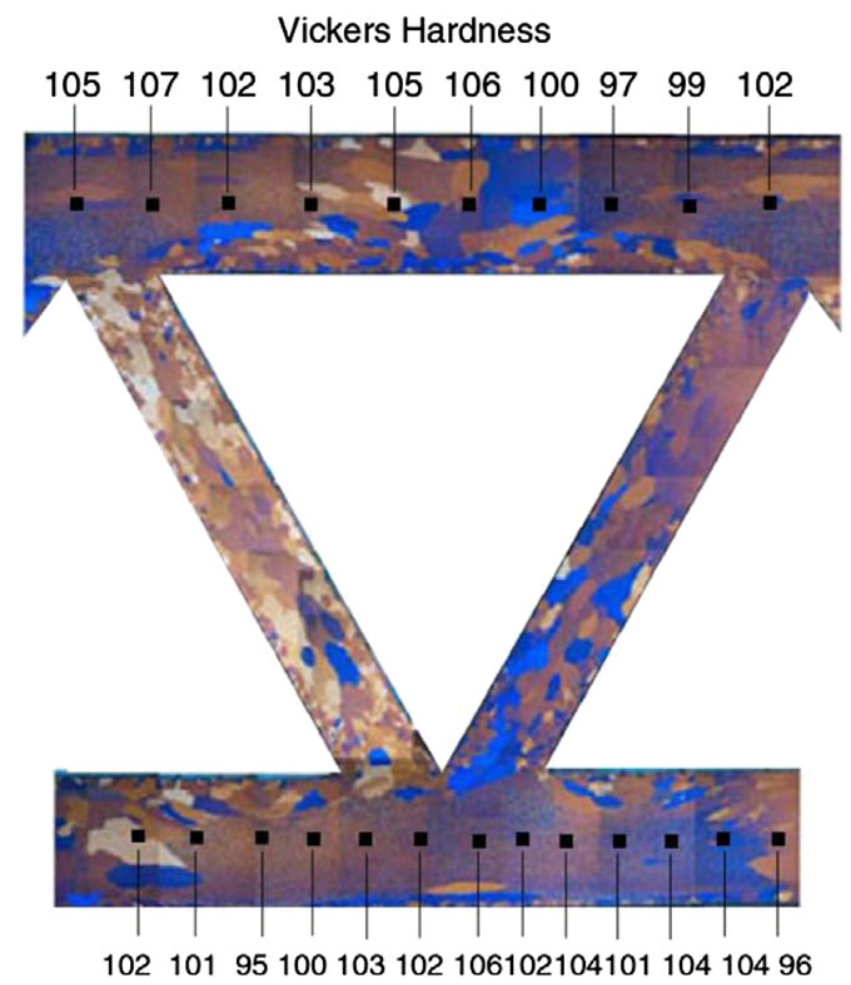

Fig. 2. A macro-image of the grain structure in the extruded sandwich panel. Micro-hardness values at various locations with the face sheets (in Vickers hardness units) are also shown. 


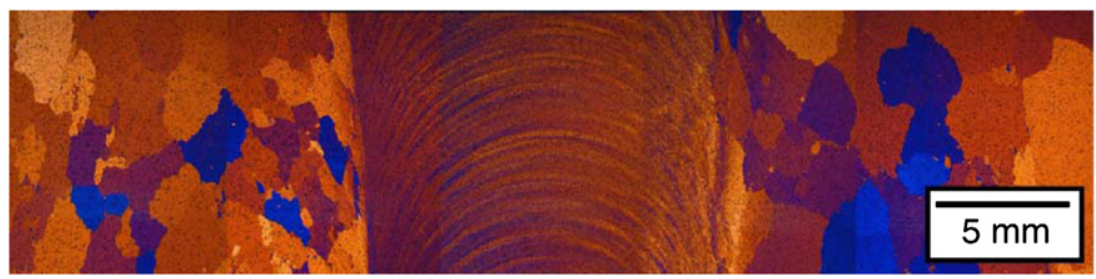

Fig. 3. A micrograph of the exterior surface of a face sheet. It shows the grain structure in and near the weld joint region. The weld tool was rotated clockwise.
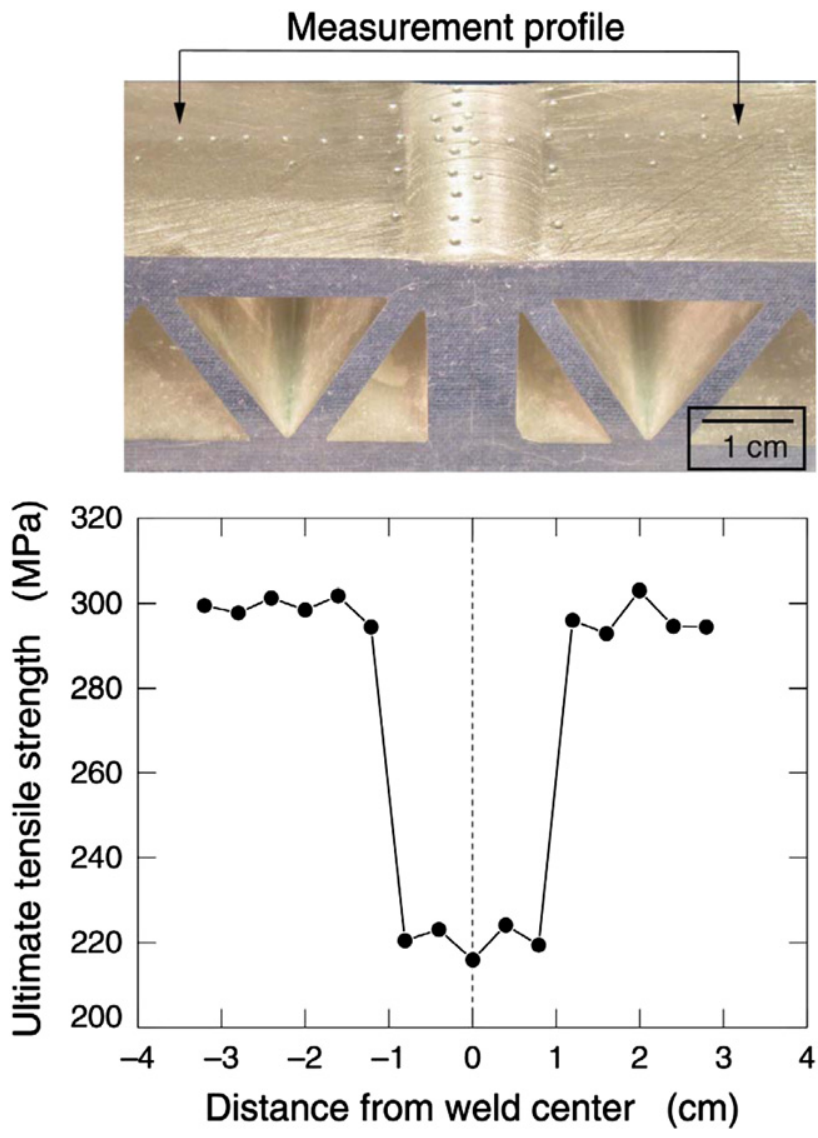

Fig. 4. Local material strength in the weld region (deduced from Rockwell B hardness measurements). A photograph of the region tested (at the same scale as the strength measurements) is also shown. The softened region extended $\pm 11 \mathrm{~mm}$ from the weld's center line.

across a welded region together with a photograph of the region tested at the same scale. It is evident that the solid state friction welding process resulted in a distinct softening of the alloy from 300 to $220 \mathrm{MPa}$ and a slight thinning of the face sheet.

Fig. 5 shows a photograph of a cross section of the weld region between a pair of sandwich panels. The weld nugget can be seen in both face sheets. The vertical webs were used to support the pressure of the tooling during the friction stir welding process and to locally stiffen the core to shield the softened faces from deformation during impulsive testing. However, comparison of the micro-hardness profile data in Fig. 4 with the photograph in Fig. 5 indicates the softened region of the face sheet extended about $1 \mathrm{~cm}$ beyond the sides of the vertical webs. This soft region may lead to strain localization and eventually fracture in the HAZ during impulsive loading and so miniature tensile testing was used to determine its mechanical properties.

\subsection{Miniature tensile coupon mechanical testing}

To characterize the mechanical properties of the alloy, quasi-static tensile tests were performed at room temperature on miniature tensile specimens extracted from the face sheets. Some of the tests were used to characterize the mechanical 


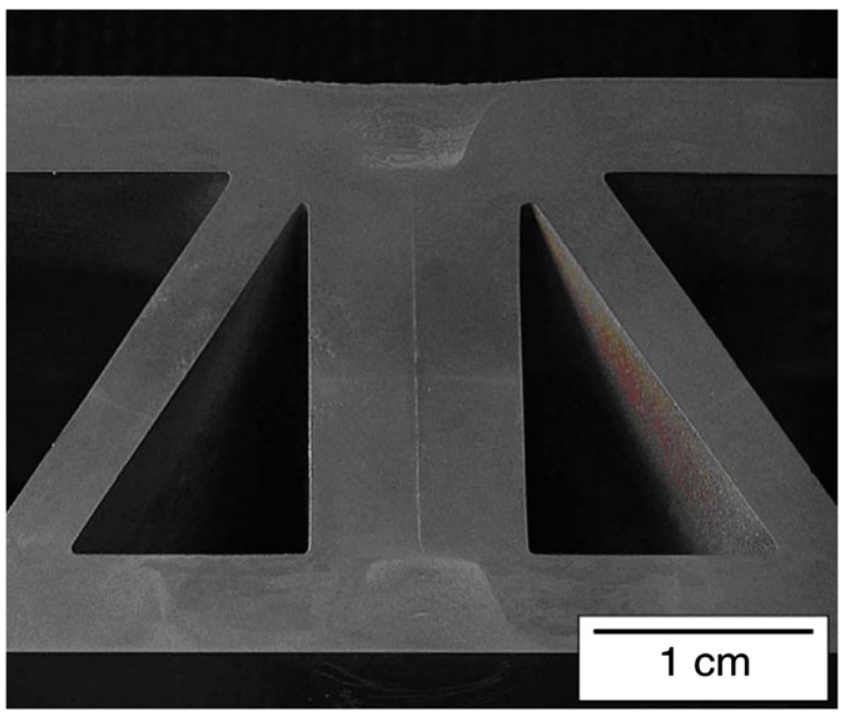

Fig. 5. Macro-photo of the friction stir weld joint cross-section. The weld nugget extended through the face sheets. The softened region extended $\pm 11 \mathrm{~mm}$ laterally from the weld center line.
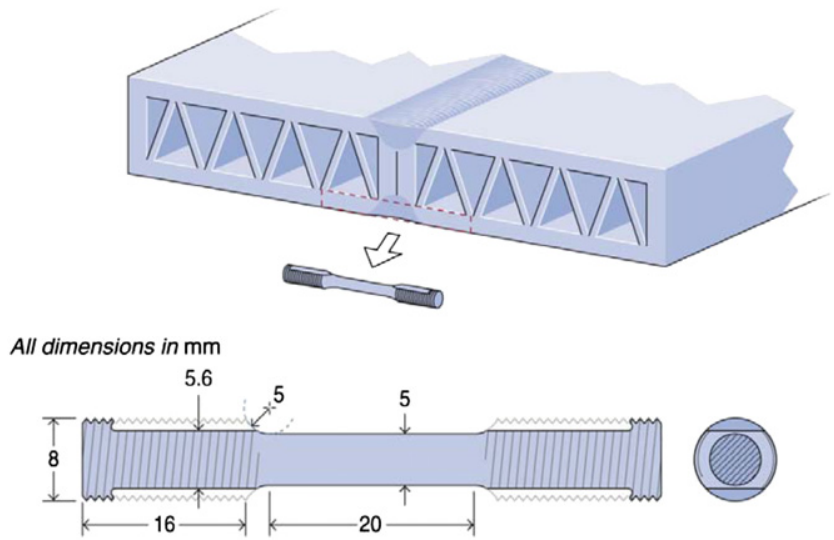

Fig. 6. Miniature tensile test specimen design used to measure the ductility and strength of the friction stir weld region (dimensions in mm). Similar tests were used to characterize the mechanical properties of the face sheet material.

properties of the parent material in the extrusion (longitudinal), transverse and $45^{\circ}$ directions. Other tests included the weld and HAZ in the gage section. The test sample geometry and location of the samples from the base material and from the weld and heat affected zone are shown in Fig. 6. The tensile tests were performed using a 20 kN DARTEC servohydraulic universal testing machine with an INSTRON 8800 controller for displacement control. The cross-head velocity of the actuator was $0.15 \mathrm{~mm} / \mathrm{min}$ in all tests, giving a strain rate of $\dot{\varepsilon}=5 \times 10^{-4} \mathrm{~s}^{-1}$ in the gage area of the specimen. During testing, the force and the diameter at minimum cross-section of the specimen were measured to fracture. A purpose-made measuring jig with two perpendicular lasers was used to accurately measure the specimen diameter reduction during straining. The lasers were installed on a mobile frame to ensure that the diameters were always measured at the minimum cross-section. The specimen diameter was measured in the thickness direction of the panel and in the transverse direction of the specimen. These diameters are denoted $D_{Z}$ and $D_{\perp}$, respectively, in the data presented below. The Cauchy (true) stress and the logarithmic (true) strain were calculated as

$$
\sigma=\frac{F}{A}, \quad \varepsilon=\ln \frac{A_{0}}{A}
$$

where $F$ is the force, $A_{0}=(\pi / 4) D_{0}^{2}$ is the initial cross-section area and $D_{0}$ is the initial diameter of the gage section. The current cross section area is then

$$
A=\frac{\pi}{4} D_{Z} D_{\perp}
$$



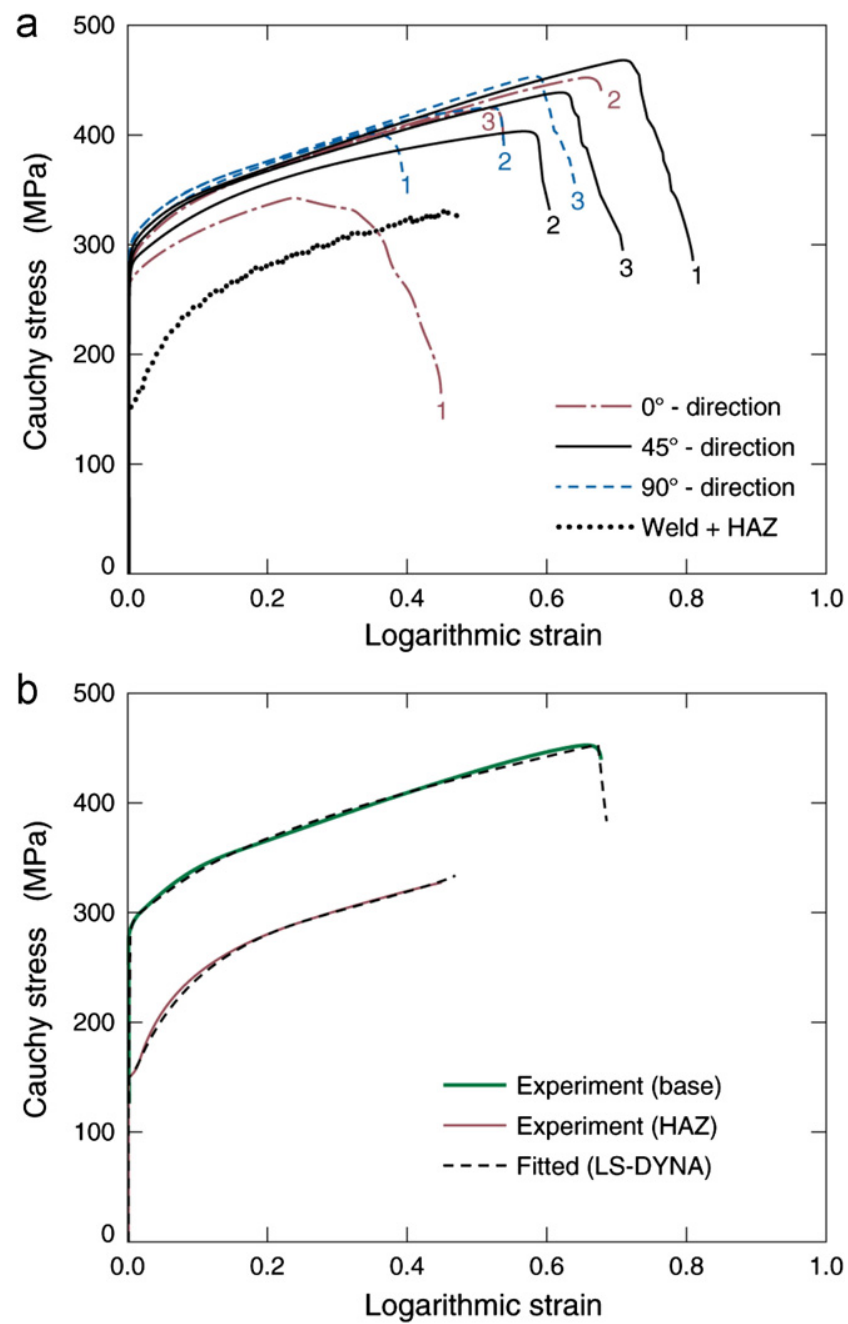

Fig. 7. (a) True stress-strain curves for samples tested in uniaxial tension to fracture at room temperature for three orientations of the specimen with respect to the extrusion direction of the panel. Similar curves from material tests that included the friction stir weld are shown for comparison. (b) Typical experimental true stress-true strain curves (measured in the $0^{\circ}$-direction with respect to the extrusion direction of the panel) for the base material and in the HAZ caused by the friction stir welding. Fitted stress-strain curves using the material models developed for subsequent numerical simulations are also shown. The flow stress is reduced by about $30 \%$ in the HAZ, and in most cases the strain to failure is considerably lower than in corresponding tests of the base material.

Since variations in stress and strain over the cross-section may occur, $\sigma$ and $\varepsilon$ should be considered as average values. The logarithmic fracture strain can be calculated as

$$
\varepsilon_{f}=\ln \frac{A_{0}}{A_{f}}
$$

where $A_{f}$ is the measured cross-section area of the specimen at failure.

The true stress-strain curves until fracture for all tensile tests are shown in Fig. 7(a). Three test results are shown for samples tested in the extrusion $\left(0^{\circ}\right)$ direction and at $45^{\circ}$ and $90^{\circ}$ to the direction of extrusion. The material properties deduced from these experiments are summarized in Table 1 . The strength level of the base materials is about the same in all orientations, indicating that the anisotropy in flow stress is relatively small. However, the true strain to fracture varies markedly both for samples of a given orientation and between tests of different specimen orientation. The highest fracture strain $\left(\varepsilon_{f}=0.81\right)$ is found in the $45^{\circ}$ direction, while the lowest fracture strain $\left(\varepsilon_{f}=0.39\right)$ occurred in the $90^{\circ}$ direction. The spread in fracture strain is significant; presumably due to the large variation in grain structure in the aluminum panels and in the miniature tensile specimens (as e.g. seen for test 1 in the $0^{\circ}$ direction). The complex microstructure of this panel is probably a result of the thick-walled and rather massive structure, making the cooling of the material after extrusion difficult to control. 
Table 1

Mechanical property data from the quasi-static tensile tests performed at room temperature.

\begin{tabular}{|c|c|c|c|c|c|c|c|c|}
\hline $\begin{array}{l}\text { Test } \\
\text { specimen } \\
\text { id. }\end{array}$ & $\begin{array}{l}\text { Initial } \\
\text { diameter } \\
(\mathrm{mm})\end{array}$ & $\begin{array}{l}\text { Yield } \\
\text { strength, } \sigma_{0.2} \\
(\mathrm{MPa})\end{array}$ & $\begin{array}{l}\text { Tensile } \\
\text { strength, } \sigma_{u} \\
(\mathrm{MPa})\end{array}$ & $\begin{array}{l}\text { Strain at maximum } \\
\text { load }(\mathrm{mm} / \mathrm{mm})\end{array}$ & $\begin{array}{l}\text { Uniaxial peak } \\
\text { true stress ( } \mathrm{MPa})\end{array}$ & $\begin{array}{l}\text { Bridgeman peak } \\
\text { true stress }(\mathrm{MPa})\end{array}$ & $\begin{array}{l}\text { True strain } \\
\text { at fracture } \\
(\mathrm{mm} / \mathrm{mm})\end{array}$ & $\begin{array}{l}\text { Fracture } \\
\text { parameter, } W_{c r} \\
(\mathrm{MPa})\end{array}$ \\
\hline $0-1$ & 3.014 & 264 & 283 & 0.094 & 343 & 333 & 0.45 & 126.3 \\
\hline $0-2$ & 3.017 & 285 & 308 & 0.103 & 450 & 439 & 0.67 & 261.7 \\
\hline $0-3$ & 3.012 & 282 & 309 & 0.107 & 424 & 412 & 0.53 & 199.3 \\
\hline $45-1$ & 3.015 & 289 & 314 & 0.087 & 470 & 459 & 0.81 & 287.6 \\
\hline $45-2$ & 3.025 & 275 & 297 & 0.116 & 399 & 388 & 0.59 & 212.9 \\
\hline $45-3$ & 3.018 & 284 & 311 & 0.091 & 438 & 427 & 0.70 & 242.2 \\
\hline $90-1$ & 3.005 & 294 & 319 & 0.076 & 403 & 391 & 0.39 & 135.4 \\
\hline $90-2$ & 3.001 & 294 & 316 & 0.101 & 427 & 415 & 0.54 & 202.3 \\
\hline $90-3$ & 3.006 & 286 & 315 & 0.100 & 454 & 443 & 0.64 & 231.8 \\
\hline FSW-1 & 4.664 & 149 & 230 & 0.211 & 329 & 302 & 0.45 & 124.6 \\
\hline FSW-2 & 4.633 & 148 & 232 & 0.201 & 331 & 305 & 0.47 & 130.5 \\
\hline FSW-3 & 4.661 & 148 & 230 & 0.221 & 326 & 299 & 0.44 & 120.8 \\
\hline
\end{tabular}
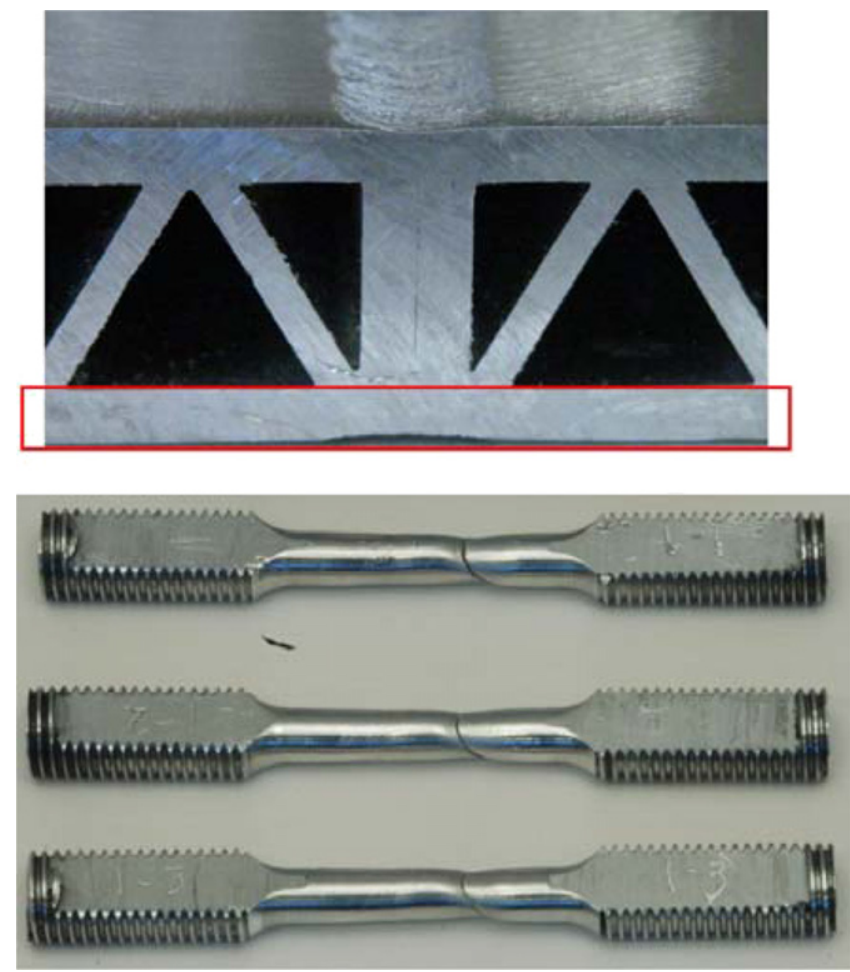

Fig. 8. Photographs of the region from which the miniature tensile specimens were obtained (denoted by the rectangular box) and three fractured specimens. The fractured specimens are shown at the same scale as the photograph of the sandwich panel from which they were extracted. All of the specimens failed in shear in the HAZ adjacent to the weld nugget after some necking.

Fig. 7(a) also shows the true stress-strain curves to fracture from tests on samples that included the friction stir weld region and the material properties deduced from these experiments are also summarized in Table 1 . There was far less spread in the stress-strain response of these samples. The flow stress is reduced by about 30\% in the HAZ, and in most cases the strain to failure is considerably lower than in corresponding tests of the base material. Fig. 8 shows pictures of fractured specimens from material tests of the friction stir weld. All the specimens failed in shear in the HAZ after some necking. Thus, it is likely that the deformation will localize to the HAZ during impulsive loading of the panels, and that failure will first take place there. It is therefore important to model this inhomogeneous material behavior in the numerical simulations of the impulse loading experiments. Fig. 7(b) shows the true stress-strain curves from two typical tests (one from the base material and one including the friction stir region) that were used to deduce the material properties for subsequent numerical simulations of the aluminum panel. A similar mechanical testing procedure was used to measure 


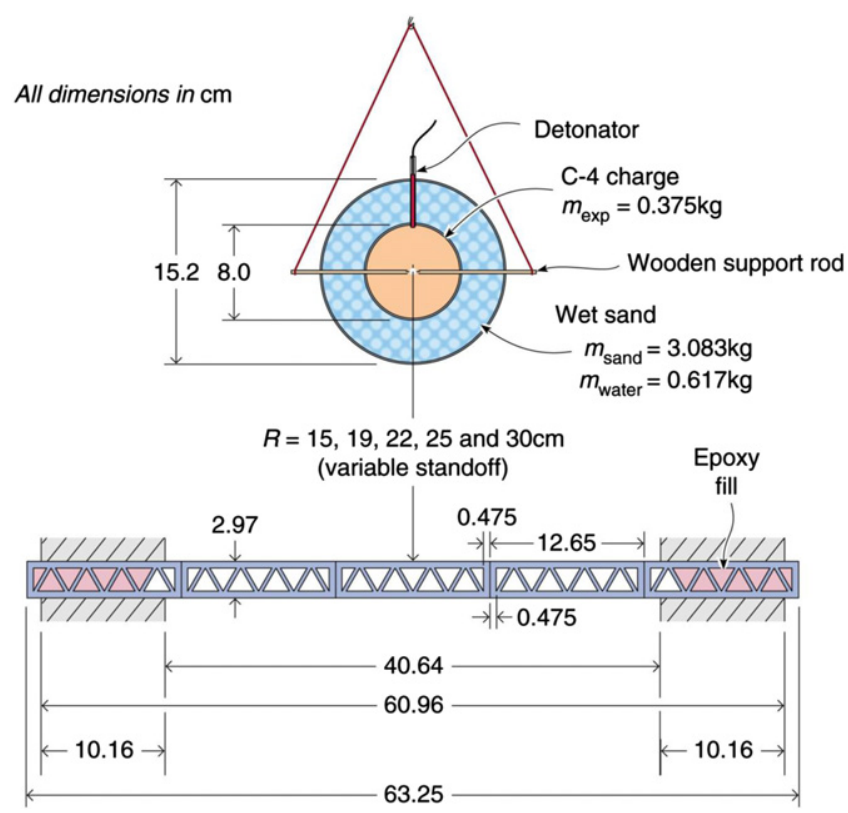

Fig. 9. The sand impulse test geometry and dimensions of the sandwich panels. A picture frame constructed from $25 \mathrm{~mm}$ thick high strength steel plates was used to rigidly clamp (bolt) the four epoxy filled edges of the test structures to the test frame.

the stress-strain response of the equivalent solid aluminum plates and to deduce the material parameters used to model their response to impulsive loading (see also Section 4).

\subsection{Dynamic test procedures}

The test panels were impulsively loaded at the Force Protection Inc. field test range (Edgefield, SC) using a model "wet sand" test charge consisting of $375 \mathrm{~g}$ of C-4 explosive surrounded by a concentric shell of water saturated, $200 \mu \mathrm{m}$ diameter glass microspheres (see Ref. Rimoli et al. (2011) for a detailed description). ${ }^{1}$ Fig. 9 shows a schematic illustration of the arrangement used for testing the corrugated core sandwich panels and equivalent mass per unit area solid plates of the same alloy. The test fixture allowed the $632 \mathrm{~mm} \times 610 \mathrm{~mm}$ sandwich panels to be fully edge clamped using a $25 \mathrm{~mm}$ thick picture frame and a series of through bolts. The region exposed to the sand impulse loading was $406 \mathrm{~mm} \times 406 \mathrm{~mm}$. The region below the samples was hollow enabling unrestricted deflection of the panel. Five sandwich panels were tested at varying charge to plate surface stand-off distances of $15 \mathrm{~cm}, 19 \mathrm{~cm}, 22 \mathrm{~cm}, 25 \mathrm{~cm}$ and $30 \mathrm{~cm}$ (defined as the distance from the spherical charge center to the impact surface of the test structure directly below the charge center). Five $17 \mathrm{~mm}$ thick monolithic 6061-T6 aluminum alloy plates of the same areal density $\left(46 \mathrm{~kg} / \mathrm{m}^{2}\right)$ as the corrugated panels were also tested at the same charge stand-off distances to allow an experimental comparison with the response of an equivalent solid plate.

The charges were made by first packing a $39 \mathrm{~mm}$ radius plastic sphere with $375 \mathrm{~g}$ of C-4 explosive. This was then positioned in the center of an $76 \mathrm{~mm}$ radius plastic sphere and the annular gap filled with $2.466 \mathrm{~kg}$ of $\sim 200 \mu \mathrm{m}$ diameter, closely packed glass microspheres, Fig. 9. A pre-calculated amount of water $(617 \mathrm{~g})$ that filled the interstices between the sand particles was then added to create a fully saturated "wet sand" test charge. Just prior to the test, a detonator was placed at the north pole of the C-4 sphere (furthest from the test sample surface) so that the detonation of the explosive preceded towards the test samples.

\subsection{Dynamic test results}

Fig. 10 shows half sections of the sandwich panels after impulsive loading by wet sand for each of the stand-off distances. It is clear that as the as the stand-off distance was decreased (intensity of the loading increased), the sandwich panel's deflection and level of damage increased. The measured center deflections of the sandwich panel's front and rear face sheets and that of the equivalent monolithic plate are summarized in Table 2 and compared as a function of the

\footnotetext{
${ }^{1}$ A model soil has been used to simplify interpretation and simulation of the experiments, and to simplify independent verification of the results by other groups.
} 

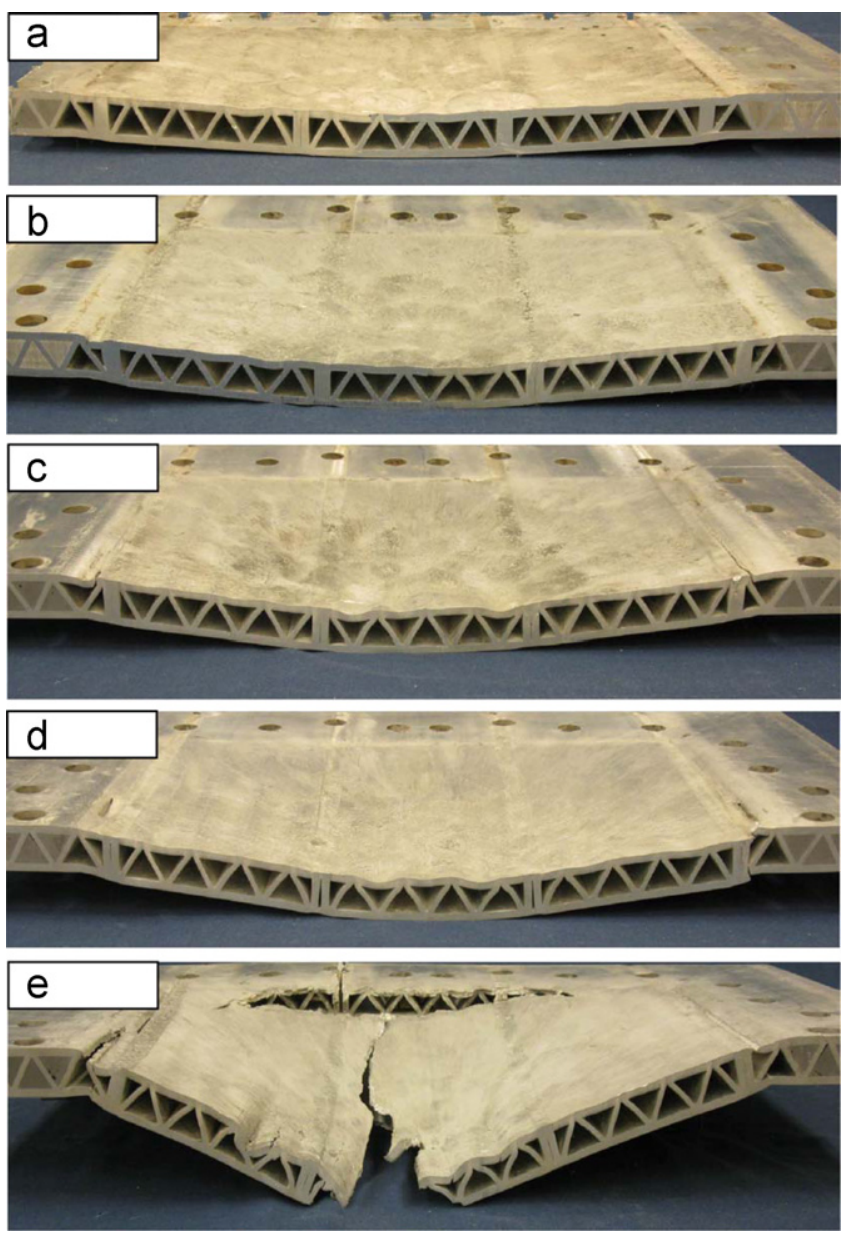

Fig. 10. Deformed experimental sandwich panel shapes for stand-off distances of (a) $30 \mathrm{~cm}$ (b) $25 \mathrm{~cm}$ (c) $22 \mathrm{~cm}$ (d) $19 \mathrm{~cm}$ and (e) $15 \mathrm{~cm}$.

stand-off distance in Fig. 11. At the closest stand-off distance of $15 \mathrm{~cm}$, the sandwich panel fractured and failed catastrophically and the measured deflections therefore consist of a component of deformation accrued while the panel was intact plus that induced as panel failure occurred (and face sheet stretching restraint was lost). For the other four stand-off distances the sandwich panels' maximum back face sheet deflections were 11-16\% less than that of the equivalent solid plate.

The corrugated core sandwich panel tested at the closest stand-off distance had undergone severe bending deformation (stretching) of both face sheets, exhibited modest buckling of the core webs and had fractured along the central regions of the four clamped sides and at the center in the panel extrusion direction. The center region of the front face sheets also underwent a significant additional (local) deflection (stretching) between the nodal connections formed by the core webs and the face sheet. This damage can be clearly seen in the higher magnification images of the mid-plane (Fig. 12(a)). It is also evident that the face sheets had begun to crack at the region of maximum stretching. Fig. 12(b) shows a close up of this fracture. Figs. 10 and 12(a) show that the degree of core compression (buckling) and face sheet stretching between nodes decreased as the stand-off distance increased. However, the large deflection of the panel tested at the $15 \mathrm{~cm}$ standoff distance was accommodated in-part by failure of the panel's four edges as well as the splitting at the panel center.

Close examination of Figs. 10 and 12(a) shows that the sandwich panels tested at a stand-off distance of 19 and $22 \mathrm{~cm}$ also suffered front face fracture on two sides of the panel. The cracks were relatively long (10 and $16 \mathrm{~cm}$ in length at the $19 \mathrm{~cm}$ stand-off test case), were located just to the side of the friction stir welds (in their heat affected zones) and had propagated parallel with the extrusion (and weld) direction. These cracks can be clearly seen in cross sections of the panel mid-planes, Fig. 12(a). An enlargement of one of these cracks is shown in Fig. 12(c) for the $19 \mathrm{~cm}$ stand-off test case. Shearoff fracture at the gripping locations of panels subjected to large stretching forces is not unexpected. However, it is evident that a significant out-of-plane force component was also present during the fracture process and contributed to the vertical displacement of the opposing fracture faces. This phenomenon is also evident upon close inspection of the panel 
Table 2

Sandwich panel and equivalent weight plate center deflections.

\begin{tabular}{|c|c|c|c|}
\hline Stand-off distance $(\mathrm{cm})$ & Sandwich front deflection $(\mathrm{cm})$ & Sandwich back deflection $(\mathrm{cm})$ & Monolithic plate deflection $(\mathrm{cm})$ \\
\hline 15 & 6.00 (failure) & 5.50 (failure) & 4.50 \\
\hline 19 & 3.50 & 3.20 & 3.60 \\
\hline 22 & 2.85 & 2.50 & 3.00 \\
\hline 25 & 2.30 & 2.15 & 2.55 \\
\hline 30 & 1.55 & 1.45 & 1.80 \\
\hline
\end{tabular}
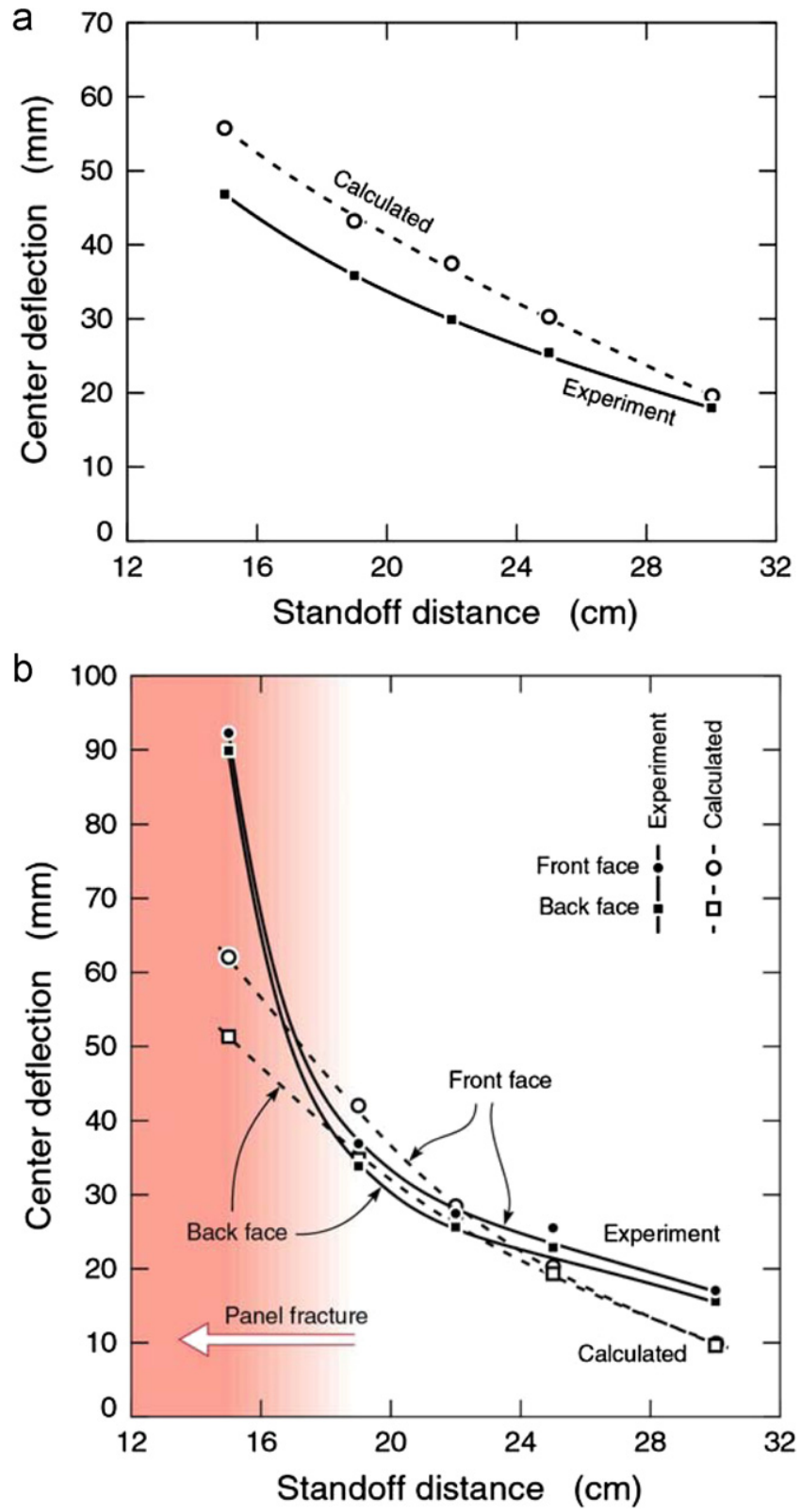

Fig. 11. Panel center deflection versus stand-off distance response for (a) the equivalent solid plate and (b) the sandwich panel structure.

tested at $25 \mathrm{~cm}$ stand-off where a vertical plastic deformation of the face sheet had occurred (Fig. 10(b)). Finally, significant thumb size indents were discovered at the four corners of the most intensely sand impacted face sheets. 


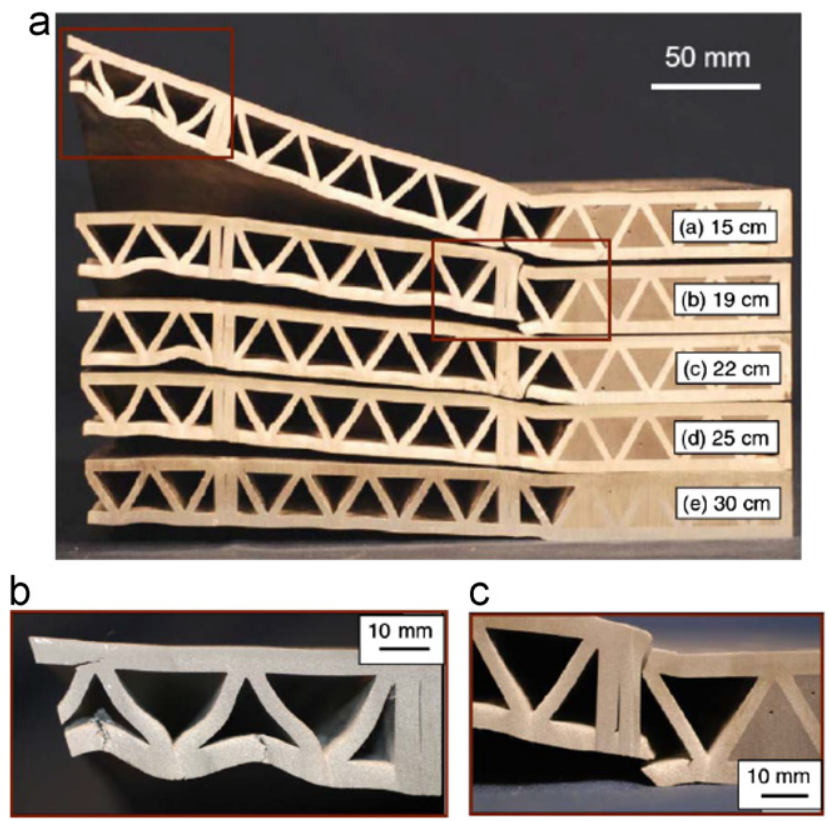

Fig. 12. (a) Cross-sectional images of the sandwich panels tested at the various stand-off distances. (b) A higher magnification view of the core buckling, front face bending between nodes and face sheet cracking near the center of the panel tested at a stand-off of $15 \mathrm{~cm}$. (c) Panel failure mode at the clamped edge of the panel tested at a stand-off of $19 \mathrm{~cm}$. Note the vertical displacement of the faces across the plane of failure.

Fig. 23(a) shows a photograph of one of the dimples in the panel tested at a stand-off of $15 \mathrm{~cm}$. The depth of the dimple depressions decreased rapidly with increase of stand-off distance, and was undetectable at a stand-off distance of $25 \mathrm{~cm}$.

\section{Numerical simulations}

\subsection{A particle based approach to model close-range blast loadings}

The IMPETUS Afea Solver (http://www.impetus-afea.com) and its discrete particle-based method, introduced in Børvik et al. (2011), has been used to model the high explosive detonation products. The particle method was inspired by the so-called corpuscular method (Olovsson et al., 2010) that was originally developed for airbag deployment simulations. The method works with discrete, rigid, spherical particles that transfer forces between each other through contact and collisions. The motivations for using a particle based approach were two-fold (Olovsson et al., 2010). First, the method is based on a Lagrangian description of motion which, in contrast to ALE and Eulerian methods, is not associated with advection related numerical errors. Second, the framework allows a simple, robust treatment of the interaction between the high explosive, the air, the soil and structural parts which are represented by finite elements. The latter is especially important for gas and soil interactions with structural parts of complex geometry. This interaction is difficult to model when working with coupled Lagrangian-ALE or Eulerian methods. We recognize that such a simple model is not applicable to general soils that contain a variety of constituents, a wide range of particle sizes and where plastic deformation of, and cohesion between, soil particles occurs. However, the simplicity of the model, and its reduced reliance upon calibration parameters, provides an opportunity to better reveal the key physics of the soil-structure interaction of primary interest here.

The particle based approach has been validated by Børvik et al. (2011) against experimental data where a spherical $150 \mathrm{~g}$ C-4 charge was detonated at various stand-off distances from a $3.4 \mathrm{~mm}$ thick stainless steel plate. The experiments were carried out for a bare charge, a charge enclosed in dry sand and a charge enclosed in fully saturated sand, and excellent agreement between predicted and experimental results was in general found. The set-up was similar to that sketched in Fig. 9. The same blast test set-up has been used in the present work to study the structural response of extruded AA6061-T6 aluminum alloy panels joined with friction stir welding, and the particle-based numerical method has been used to explore the key phenomena induced in these experiments.

\subsection{Modeling of high explosive (C-4) and saturated soil}

The modeling of high explosive detonation products, air, dry and saturated soils and structural parts using discrete particles was described in detail in Børvik et al. (2011), and only the main features regarding the modeling of high explosives (C-4) and saturated wet soil will be repeated in the following for completeness. The finite element model of the problem to be simulated is summarized in Fig. 13. The method is inspired by Olovsson et al. (2010), and the numerical 


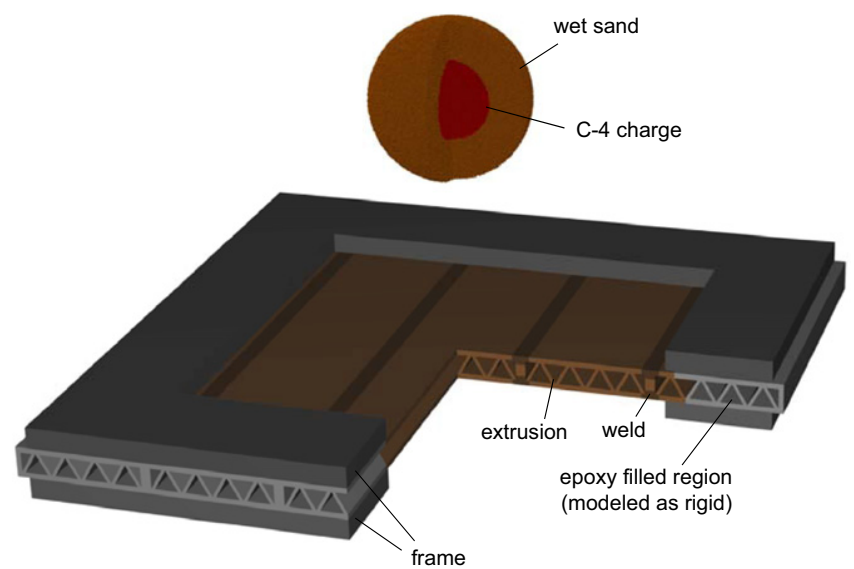

Fig. 13. General view of finite element model prior to charge detonation.

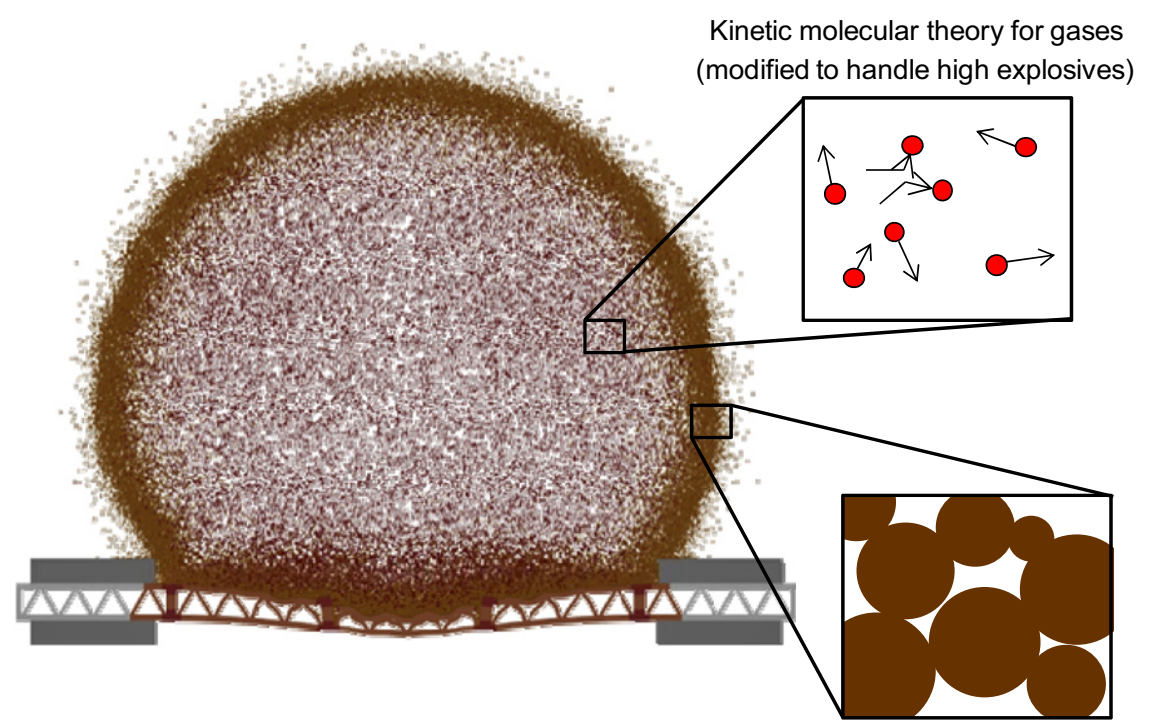

Discrete grains in contact. Grain size distribution, friction, damping and contact stiffness are adapted to match a given EOS.

Fig. 14. Synopsis of numerical modeling approach.

modeling approach is illustrated in Fig. 14. Since that work, co-volume effects investigated by Clausius (1880) and Baibuz et al. (1986), have been added for a better gas behavior at extreme pressures. The method has also been extended to account for high gas flow velocities which profoundly affect how the gas-gas particle interaction is handled (Maxwell, 1860). However, the basic idea of modeling the gas as interacting rigid particles remains the same.

The parameters necessary to define a discrete particle model of a high explosive are the initial density $\rho_{0}$, the initial internal energy $E_{0}$, the ratio of heat capacities at constant pressure and volume $\gamma=C_{P} / C_{V}$, and the initial solid-fill fraction of the particles $b$. A significant solid-fill fraction gives rise to a co-volume effect that drastically increases the pressure at high densities. The parameters used in the discrete particle model of C- 4 detonation were determined by fitting to the response of a simulated cylinder test (see Olovsson et al., 2010). The cylinder test consisted of a pipe made of OHFC copper that was filled with the high explosive to be characterized. The explosive was initiated at one end, whereupon a detonation wave traveled along the pipe (prescribed by a programmed burn algorithm). The pipe wall motion is monitored and its radial velocity at various locations along the pipe axis can be used to determine the properties of the high explosive. Experimental data from a cylinder test using C-4 together with optimized JWL-EOS parameters were presented by Souers et al. (1996). Fitted constants for the discrete particle-based method for C-4 are given in Table 3. Excellent agreement between the measured and predicted velocity-time curve in the cylinder test was obtained.

The soil was modeled differently to the high explosive gases. In this case, a penalty based contact was used instead of simple elastic collisions. The contact law incorporated both friction and damping, and the rheological model of the soil is 
Table 3

Discrete particle-based constants for C-4.

\begin{tabular}{llll}
\hline$\rho_{0}\left(\mathrm{~kg} / \mathrm{m}^{3}\right)$ & $D(\mathrm{~m} / \mathrm{s})$ & $\gamma($ dimensionless $)$ & $b($ dimensionless $)$ \\
\hline 1601 & 8190 & 1.3 & $E_{0}\left(\mathrm{GJ} / \mathrm{m}^{3}\right)$ \\
\hline
\end{tabular}

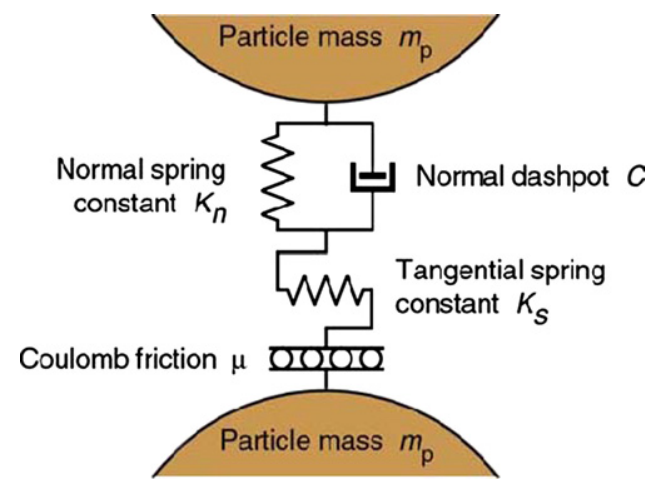

Fig. 15. Schematic of the rheological model used for the particle interactions.

shown in Fig. 15. Note that the wet soil is modeled without friction. In a real soil, energy dissipates through both friction and crushing. There is no crushing in the discrete particle model and elasticity is not represented by real elastic properties of the soil material, but by the penalty stiffness $k$ for the contact. The saturated soil consisted of small soda lime glass spheres with a diameter of $200 \mu \mathrm{m}$ and density of $2700 \mathrm{~kg} / \mathrm{m}^{3}$. The initial solid fill fraction was $60 \%$, which gives an initial soil density of $1620 \mathrm{~kg} / \mathrm{m}^{3}$. The rest of the volume was filled by water. This gives an initial density of the saturated soil of $2020 \mathrm{~kg} / \mathrm{m}^{3}$. Note that saturated soil has no room for compaction and so the pressure builds up rapidly. Since uniformly sized spheres can be packed to a solid fill fraction of only $60 \%$, a slight variation in particle radius ( $\pm 2.5 \%$ ) was used to achieve a denser packing of $64 \%$ like that of the experiments.

The soil model was characterized in several simulation steps by monitoring the stresses during uniaxial compression of a unit cell with 1000 particles and periodic boundary conditions (see Børvik et al. (2011) for a full description of the procedure). Since no real compression test data for the saturated soil used in these tests are available, it was decided to simply test a few reasonable combinations of contact stiffness and damping. Observations by Deshpande et al. (2009) indicate that saturated soil ejecta does not turn into a loose spray as the compressive wave reflects into tension at the free surface. For this reason it was decided to utilize a contact damping rather than friction law in the saturated soil model (Børvik et al., 2011).

\subsection{Finite element model}

The finite element mesh of the extruded aluminum panel and the frame was built up from 26,112 64-node 3rd-order and 29,640 8-node linear hexahedra elements, resulting in a model with a total of 966,408 nodes. Linear elements were used for the picture frame gripping system and for the clamped parts of the panel contained within the grips. In the experiments, the core of the sandwich in the edge clamped regions of the test structure was filled with epoxy to avoid local yielding of the face sheets at the bolt connections to the picture frame supports. In the numerical model the epoxy filled regions were simplified by switching the material from deformable to rigid. Perfect clamping and no relative sliding between the plates and support frame were permitted. The node spacing in the deformable part of the plate ranged between $0.6 \mathrm{~mm}$ and $2.7 \mathrm{~mm}$. To visualize failure and propagation of cracks, elements were eroded when at least 16 out of 64 integration points (for the 3rd-order hexahedra elements) reached the failure criterion described in Section 4.1. The results are not sensitive to variations in this element erosion criterion, since an element quickly loses its load carrying capacity as soon as failure has been reached at a few integration points. The simulations of the solid aluminum plates used a 368,373 node model constructed from four 3rd order hexa elements through thickness of the plate. The minimum/ maximum in-plane node spacing was $1.6 \mathrm{~mm} / 3.3 \mathrm{~mm}$ with the smaller value located along the rim of the plate.

\section{Material modeling}

\subsection{Constitutive relations and fracture criterion}

A modified version of the Johnson-Cook constitutive relation (or the MJC model) was chosen to model the target material (Børvik et al., 2001; Johnson and Cook, 1983). Thus, the constitutive behavior of the alloy is assumed to be 
isotropic. The von Mises equivalent stress is expressed as

$$
\sigma_{e q}=\left(\sigma_{0}+Q_{1}\left[1-\exp \left(-C_{1} \varepsilon_{e q}\right)\right]\right)\left(1+\dot{\varepsilon}_{e q}^{*}\right)^{C}\left(1-T^{* m}\right)
$$

where $\varepsilon_{e q}$ is the equivalent plastic strain and $\sigma_{0}, Q_{1}, C_{1}, C$ and $m$ are material constants. Note that in this study the usual Johnson-Cook strain hardening law in Eq. (4) has been replaced by a one-term Voce strain hardening law. The dimensionless plastic strain rate is given by $\dot{\varepsilon}_{e q}^{*}=\dot{\varepsilon}_{e q} / \dot{\varepsilon}_{0}$, where $\dot{\varepsilon}_{0}$ is a user-defined reference strain rate. The homologous temperature is defined as $T^{*}=\left(T-T_{r}\right) /\left(T_{m}-T_{r}\right)$, where $T$ is the absolute temperature, $T_{r}$ is the ambient temperature and $T_{m}$ is the melting temperature. The temperature change due to adiabatic heating is calculated as

$$
\Delta T=\int_{0}^{\varepsilon_{e q}} \chi \frac{\sigma_{e q} d \varepsilon_{e q}}{\rho C_{p}}
$$

where $\rho$ is the material density, $C_{p}$ is the specific heat and $\chi$ is the Taylor-Quinney coefficient that represents the proportion of plastic work converted into heat.

Fracture was modeled using a criterion proposed by Cockcroft and Latham (CL) (Cockcroft and Latham, 1968) in which failure was assumed to occur when the integral of the maximum principal tensile stress along the plastic strain path reached a critical value. The damage in an element is given as

$$
D=\frac{W}{W_{c r}}=\int_{0}^{\varepsilon_{e q}} \frac{\left\langle\sigma_{1}\right\rangle d \varepsilon_{e q}}{W_{c r}} \leq 1
$$

where $\sigma_{1}$ is the major principal stress, $\left\langle\sigma_{1}\right\rangle=\sigma_{1}$ when $\sigma_{1} \geq 0$ and $\left\langle\sigma_{1}\right\rangle=0$ when $\sigma_{1}<0$. Therefore, damage does not grow, and fracture cannot occur when there is no tensile stress operating. It is further evident that the CL criterion includes the unilateral condition and further depends on both the stress triaxiality and the Lode parameter through the positive part of the major principal stress (Kane et al., 2011). The critical value of $W$, denoted $W_{c r}$, can be determined from a single uniaxial tensile test and is simple to implement in finite element codes. The CL failure criterion has been shown to give equally good results as both MJC (Dey et al., 2006) and continuum damage-mechanics based (Kane et al., 2011) failure criteria in ballistic perforation studies of steel and aluminum plates. We also note that it would be difficult to model the entire panel structure with a continuum damage-based constitutive model such as a modified Gurson model (Nashon and Hutchinson, 2008) or other approaches. Accurate predictions of fracture with such models require a mesh much finer than those for criteria based on a critical plastic strain or plastic work, and would simply make the present computational problem computationally costly to solve. It is essential when using CL or MJC criteria, that they be calibrated against data from a test that produces failure in a manner similar to that occurring in the application. The shearing failure in the tensile test of the stir welded material appears to be representative of the shear-off failures experienced in the blast tests.

\subsection{Identification of material constants}

To determine the material constants in the constitutive relation and fracture criterion for the base material, one typical tensile test (see Figs. 6 and 7b) in the $0^{\circ}$-direction with respect to the extrusion direction of the panel was modeled using the finite element method. These tests were carried out at a quasi-static strain rate and at room temperature. The finite element analysis was conducted using the explicit solver of the non-linear FE code LS-DYNA, ${ }^{2}$ and mass-Scaling was applied to increase the critical time step. Four-node axisymmetric elements with one integration point and a stiffnessbased hourglass control were used in all finite element models. The characteristic element size in the gage area was $0.075 \mathrm{~mm}$, giving 20 elements over the gage radius. This was a significantly smaller element size than used for panel simulations. Element erosion was used in the simulations to remove elements when the fracture criterion $W=W_{c r}$ was reached.

The inverse modeling was carried out in several simulation steps. Firstly, the measured true stress-true plastic strain curve was used to determine the yield stress $\sigma_{0}$ and to establish initial values for the strain hardening constants using a curve fit to Bridgman corrected data. In the fit, the strain-rate sensitivity constant $C$ was given a small positive value, $\dot{\varepsilon}_{0}$ was taken equal to the strain rate in the quasi-static tensile tests, while the Taylor-Quinney coefficient $\chi$ was set to zero (assuming isothermal conditions). Secondly, the strain hardening constants, $Q_{1}$ and $C_{1}$, were adjusted by trial and error to give a good fit to the measured strain hardening curve. The predicted curve was determined in an exactly similar way as in the experiment (Section 2.3). Finally, the CL parameter $W_{c r}$ was adjusted to give fracture at the same location as in the physical test. Fig. 7(b) gives a comparison between the predicted and the experimental stress-strain response curve after the fit. The agreement is good, and the fitted material constants for the base material in the sandwich panels are given in Table 4 together with physical constants taken from the literature. The material parameter $m$ was set to unity, implying a linear decrease in flow stress with increasing temperature, since adiabatic conditions will be applied in the blast simulations to follow.

To determine the material constants for the material in the friction stir weld (FSW), the same procedure as described above was carried out using a typical test over the weld zone (see Fig. 6). Fig. 7(b) gives a comparison between the

\footnotetext{
${ }^{2}$ A general purpose multi-physics code provided by the Livermore Software Technology Corporation (LSTC).
} 
Table 4

Material constants (based on inverse modeling) in the $0^{\circ}$ direction of the base material for the AA6061-T6 aluminum sandwich panel.

\begin{tabular}{|c|c|c|c|c|c|c|c|c|c|c|c|c|c|}
\hline \multicolumn{3}{|c|}{$\begin{array}{l}\text { Elastic constants and } \\
\text { density }\end{array}$} & \multicolumn{3}{|c|}{$\begin{array}{l}\text { Yield stress and strain } \\
\text { hardening }\end{array}$} & \multicolumn{2}{|c|}{$\begin{array}{l}\text { Strain rate } \\
\text { hardening }\end{array}$} & \multicolumn{5}{|c|}{ Temperature softening and adiabatic heating } & \multirow{2}{*}{$\begin{array}{l}\text { Fracture parameter } \\
W_{c r}(\mathrm{MPa})\end{array}$} \\
\hline$E(\mathrm{GPa})$ & $v$ & $\rho\left(\mathrm{kg} / \mathrm{m}^{3}\right)$ & $\sigma_{0}(\mathrm{MPa})$ & $Q_{1}(\mathrm{MPa})$ & $C_{1}$ & $\dot{\varepsilon}_{0}\left(\mathrm{~s}^{-1}\right)$ & C & $T_{r}(\mathrm{~K}) T_{m}(\mathrm{~K})$ & $m$ & $C_{p}(\mathrm{~J} / \mathrm{kg} \mathrm{K})$ & $\chi$ & $\alpha\left(\mathrm{K}^{-1}\right)$ & \\
\hline 70 & 0.3 & 2700 & 290 & 90 & 7.5 & $5 \times 10^{-4}$ & 0.001 & $293 \quad 893$ & 1 & 910 & 0.9 & $2.3 \times 10^{-5}$ & 342 \\
\hline
\end{tabular}

Table 5

Material constants (based on inverse modeling) in the HAZ of the friction stir weld for the AA6061-T6 aluminum sandwich panel.

\begin{tabular}{|c|c|c|c|c|c|c|c|c|c|c|c|c|c|c|}
\hline \multicolumn{3}{|c|}{$\begin{array}{l}\text { Elastic constants and } \\
\text { density }\end{array}$} & \multicolumn{3}{|c|}{$\begin{array}{l}\text { Yield stress and strain } \\
\text { hardening }\end{array}$} & \multicolumn{2}{|c|}{$\begin{array}{l}\text { Strain rate } \\
\text { hardening }\end{array}$} & \multicolumn{6}{|c|}{ Temperature softening and adiabatic heating } & \multirow{2}{*}{$\begin{array}{l}\text { Fracture parameter } \\
W_{c r}(\mathrm{MPa})\end{array}$} \\
\hline$E(\mathrm{GPa})$ & $v$ & $\rho\left(\mathrm{kg} / \mathrm{m}^{3}\right)$ & $\sigma_{0}(\mathrm{MPa})$ & $Q_{1}(\mathrm{MPa})$ & $C_{1}$ & $\dot{\varepsilon}_{0}\left(\mathrm{~s}^{-1}\right)$ & C & $T_{r}(\mathrm{~K})$ & $T_{m}(\mathrm{~K})$ & $m$ & $C_{p}(\mathrm{~J} / \mathrm{kg} \mathrm{K})$ & $\chi$ & $\alpha\left(\mathrm{K}^{-1}\right)$ & \\
\hline 70 & 0.3 & 2700 & 150 & 155 & 9.2 & $5 \times 10^{-4}$ & 0.001 & 293 & 893 & 1 & 910 & 0.9 & $2.3 \times 10^{-5}$ & 142 \\
\hline
\end{tabular}

Table 6

Material constants for the $17 \mathrm{~mm}$ thick monolithic AA6061-T6 aluminum plate.

\begin{tabular}{|c|c|c|c|c|c|c|c|c|c|c|c|c|c|c|}
\hline \multicolumn{3}{|c|}{$\begin{array}{l}\text { Elastic constants and } \\
\text { density }\end{array}$} & \multicolumn{3}{|c|}{$\begin{array}{l}\text { Yield stress and strain } \\
\text { hardening }\end{array}$} & \multicolumn{2}{|c|}{$\begin{array}{l}\text { Strain rate } \\
\text { hardening }\end{array}$} & \multicolumn{6}{|c|}{ Temperature softening and adiabatic heating } & \multirow{2}{*}{$\begin{array}{l}\text { Fracture parameter } \\
W_{c r}(\mathrm{MPa})\end{array}$} \\
\hline$E(\mathrm{GPa})$ & $v$ & $\rho\left(\mathrm{kg} / \mathrm{m}^{3}\right)$ & $\sigma_{0}(\mathrm{MPa})$ & $Q_{1}(\mathrm{MPa})$ & $C_{1}$ & $\dot{\varepsilon}_{0}\left(\mathrm{~s}^{-1}\right)$ & $C$ & $T_{r}(\mathrm{~K})$ & $T_{m}(\mathrm{~K})$ & $m$ & $C_{p}(\mathrm{~J} / \mathrm{kg} \mathrm{K})$ & $\chi$ & $\alpha\left(\mathrm{K}^{-1}\right)$ & \\
\hline 70 & 0.3 & 2700 & 270 & 98 & 6.0 & $5 \times 10^{-4}$ & 0.001 & 293 & 893 & 1 & 910 & 0.9 & $2.3 \times 10^{-5}$ & 278 \\
\hline
\end{tabular}

predicted and the experimental stress-strain response of the weld material after the fit, while fitted model constants are given in Table 5. The agreement is again seen to be good. A similar procedure was used to deduce the material parameters of the solid aluminum plate (Table 6).

\section{Numerical results}

In the numerical simulations 400,000 particles were used to model the sand and 80,000 particles were used to model the high explosive, while a contact stiffness of $k_{o}=4 \mathrm{GN} / \mathrm{m}$ and a damping coefficient of $\xi=0.005$ were applied in the rheological model. These numbers were picked based on the convergence study presented in Børvik et al. (2011). To assess the chosen number of particles, a simulation at a stand-off distance of $15 \mathrm{~cm}$ with a reduced number of particles $(200,000$ sand and 40,000 C-4 particles) was also carried out. The transferred impulse differed by less than $1 \%$ from the simulation with twice as many particles.

Fig. 16(a) shows the time history of the simulated impulse transferred to a sandwich panel for three different values of stand-off distance. In the simulations, the impulses are calculated by integrating the particle-structure contact forces in time. The impulse rise time was about $0.1 \mathrm{~ms}$. The total impulse acquired by the panels is plotted as a function of stand-off distance in Fig. 16(b). It varied with stand-off because of inverse square law spreading of the sand front and FSI effects to be discussed below. The final plate deflection was obtained by splitting the event into two simulation steps. Step 1 was the loading phase where wet sand was accelerated by the detonation products and eventually interacted with the deforming plate. Step 1 was terminated after $2 \mathrm{~ms}$. At this point in time there was no more interaction between the sand and the plate. The plate had already reached its peak deflection and it had begun vibrating elastically. In Step 2 the detonation products and the soil were removed, mass damping was added, and the simulation was continued until the plate came to rest. A penalty based contact formulation was used for the clamping of the plate. The rim of the plate was modeled as rigid so no sliding could occur in either step. Hence, the clamping force and coefficient of friction were irrelevant in the simulations.

Fig. 17 shows the deformed panels at the end of the simulations for the stand-off distances used in the experiments. The simulations show panels that have been sectioned across the middle of the panel and use a perspective similar to that of the experimentally tested panels (Fig. 10). The simulations encouragingly captured many of the phenomena observed experimentally including an increase in panel center deflection with reduction in stand-off distance, the development of edge cracks (in the HAZs adjacent to the friction stir welds) on two of the panel sides for the panels tested at stand-off distances of 22 and $19 \mathrm{~cm}$, the appearance of edge cracks along the four panel edges at a stand-off distance of $15 \mathrm{~cm}$ and 

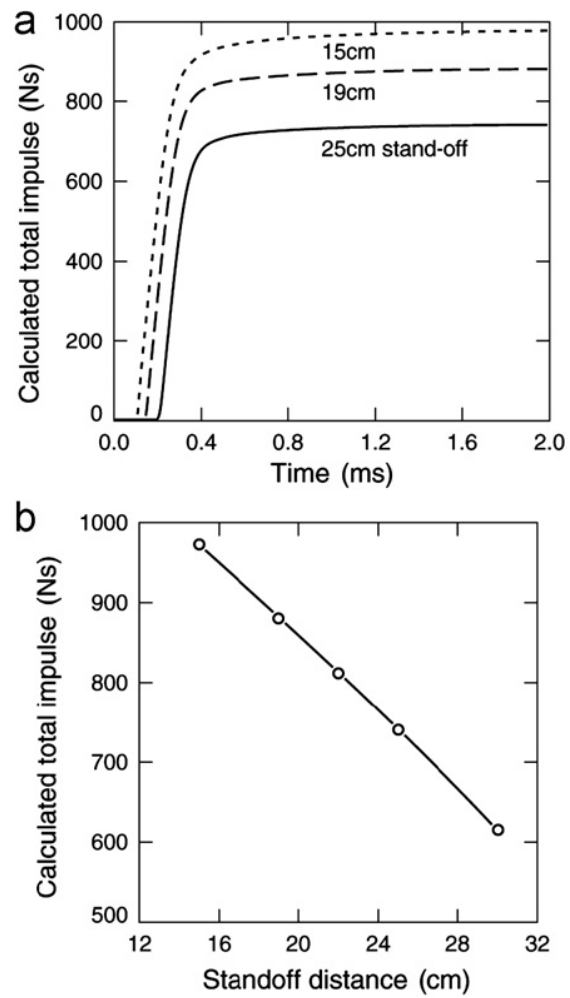

Fig. 16. (a) Predicted impulse-time history applied to the sandwich panels at stand-off distances of 15,19 and $25 \mathrm{~cm}$ and (b) the effect of stand-off distance upon the total impulse applied by the sandwich panels.
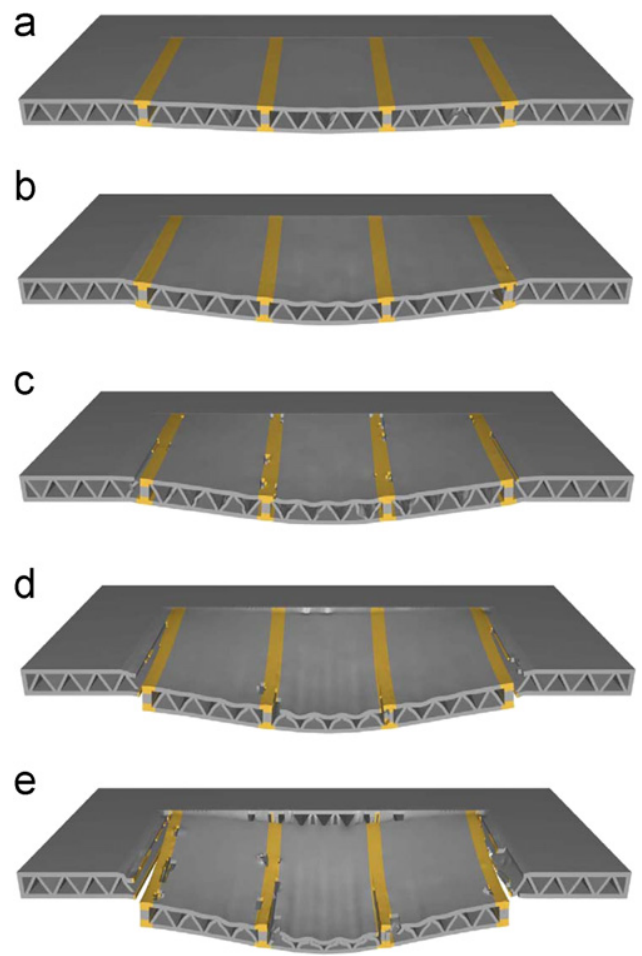

Fig. 17. Deformed sandwich panel shapes obtained from IMPETUS Afea Solver simulations for stand-off distances of (a) $30 \mathrm{~cm}$, (b) $25 \mathrm{~cm}$, (c) $22 \mathrm{~cm}$, (d) $19 \mathrm{~cm}$, and (e) $15 \mathrm{~cm}$. The yellow regions identify the HAZ in the finite element model. (For interpretation of the references to color in this figure legend, the reader is referred to the web version of this article.) 
a

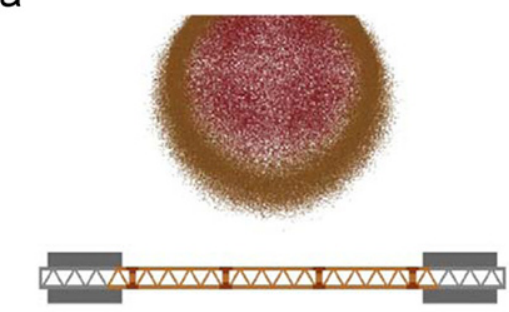

C

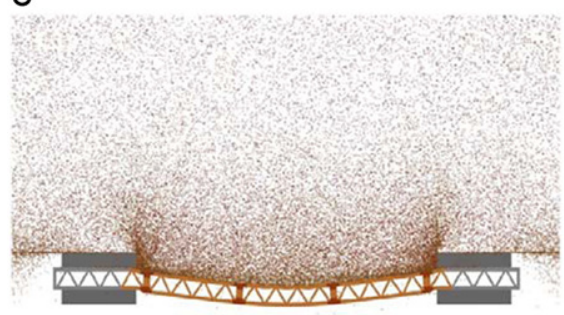

b

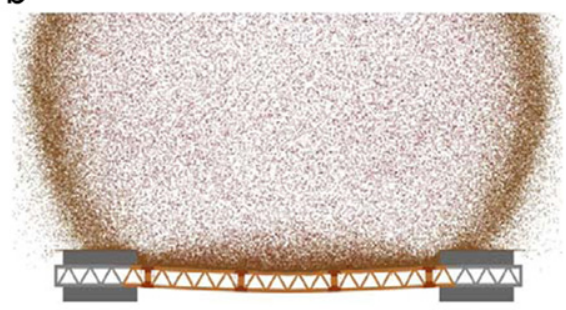

d

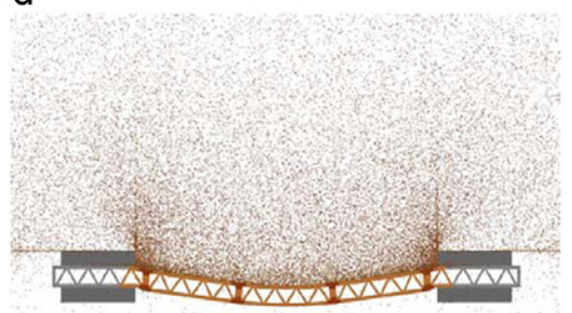

Fig. 18. Time resolved interaction of sand particles with a sandwich structure at a stand-off distance of $25 \mathrm{~cm}$. Results are shown for a thin slice of the modeled problem that passes through the center of the test charge and the sandwich structure transverse to the welding direction. (a) $t=0.1$ ms, (b) $\mathrm{t}=0.3 \mathrm{~ms}$, (c) $\mathrm{t}=0.5 \mathrm{~ms}$ and (d) $\mathrm{t}=0.7 \mathrm{~ms}$.

the appearance of center panel splitting in the $15 \mathrm{~cm}$ stand-off case. The simulations also led to a similar level of web buckling and core compression to that seen in the experiments.

The simulated panel deflections for both the sandwich panels and similar simulations for the equivalent solid plates are compared with measured values in Fig. 11. The solid plate data shown in Fig. 11(a) provide an estimate of the predictive accuracy for a system where panel fracture did not contribute to the system response. The simulations over predicted the deflections by up to $10-15 \%$ for the most intensely loaded example. The simulated permanent deflections of the center of the front and back faces of the sandwich panels are compared with the experimental data in Fig. 11(b). In general good agreement is observed until the onset of panel splitting at the shortest stand-off distance. At this point the impulse transferred to the panels is very sensitive to the rate of panel fracture which is in turn strongly coupled to the panel deformation dependent soil-structure interaction.

Insight into the complex nature of the sand particle-panel interaction can be gained by examining the effects of standoff distance upon the reflection of the sand. Fig. 18 shows time resolved "snap shots" of mid-plane sandwich panel deformation and sand particle locations during the interaction process at the $25 \mathrm{~cm}$ stand-off distance. The sand first impacts the center of the panel (about $0.13 \mathrm{~ms}$ after detonation) at near normal incidence to the panel surface. The expanding shell then loads the remainder of the panel with an increasingly glancing angle of impact. The sand shell reached the picture frame panel gripping system at just under $0.3 \mathrm{~ms}$ after detonation. A high sand particle volume fraction is evident just above the already deflecting front face sheet in the result shown in Fig. 18(b). This corresponds to the sand densification regime recently identified in the sand slug simulations of Pingle et al. (2012). While the sand at the center of the panel is vertically reflected and transfers significant momentum to the panel, the sand that impacts nearer the periphery of the sample is more obliquely reflected with less effective momentum transfer to the plate. This obliquely reflected sand travels laterally across the sample surface and eventually reaches the vertical boundary of the picture frame clamping system and is reflected perpendicularly away from the sample surface (Fig. 18(c)). A vertical momentum must be created in the sandwich panel surface to balance that of the outward propagating sand particles and this adds to the vertical impulse from the downward component of the incident sand that directly impacted this region.

As the charge is moved closer to the sample surface (see Fig. 19), the fraction of sand particles that impact the panel increase, and the total impulse transmitted to the panel rises (as also shown in Fig. 16). The interaction of the sand with the dynamically deforming panel and its rigid picture frame clamping system also changes. The sand first impacts the face sheet at $\sim 0.1 \mathrm{~ms}$ after detonation (because of the short travel distance) and quickly causes significant deflection (and core crushing) of the front face. By $0.3 \mathrm{~ms}$, the panel has already begun to suffer a large amplitude bending deflection accommodated by significant stretching of the front and rear face sheets and the core. Both the macroscopic (panel scale) and inter-nodal face sheet deflections change both the angle (obliquity) of contact of the delayed arrival sand and details of the sand reflection process. The sand that is reflected laterally over the front face sheet is again very strongly reflected perpendicular to the panel upon impact with the picture frame clamps (Fig. 19(b) and (c)). Fracture, and an associated downward deflection of the panel at the clamping locations, changes the details of the reflection process and the local impulse intensity. Similar effects can eventually be seen at fracture locations towards the panel center (Fig. 19(d)). 
a

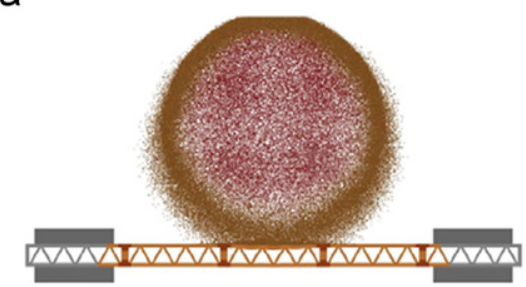

C

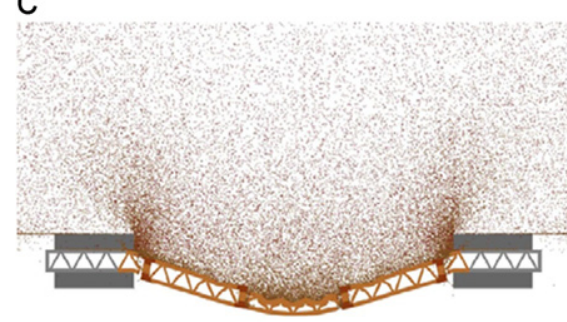

b

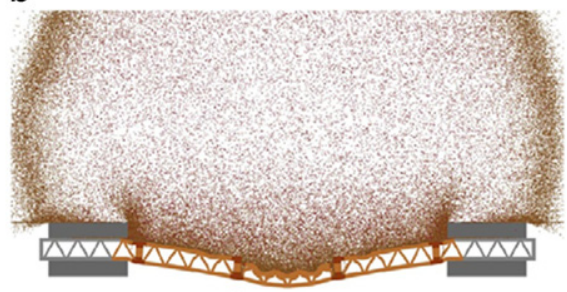

d

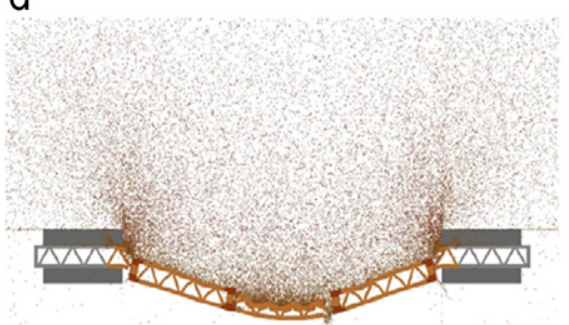

Fig. 19. Time resolved interaction of sand particles with a sandwich structure at a stand-off distance of $15 \mathrm{~cm}$. Results are shown for a thin slice of the modeled problem that passes through the center of the test charge and the sandwich structure transverse to the welding direction. (a) $t=0.1$ ms, (b) $\mathrm{t}=0.3 \mathrm{~ms}$, (c) $\mathrm{t}=0.5 \mathrm{~ms}$ and $(\mathrm{d}) \mathrm{t}=0.7 \mathrm{~ms}$.

The specific impulse can be calculated as a function of position at various times during impulsive sand loading of the sandwich panels. Fig. 20 shows representative results for a stand-off distance of $19 \mathrm{~cm}$. The anticipated bull's eye pattern of loading centered directly below the center of the charge is evident in these results and its increase over time is also clear. However, close examination of the results shows that the highest intensity impulse does not occur at the sample center. Instead, the most intense specific impulse is found at the sides of the sample where upward sand reflection (from the picture frame clamps) occurs. Local increases in specific impulse can also be seen at the center of the panel. These are extended in the extrusion direction. A high specific impulse is surprisingly observed at the corners of the panels (furthest removed, and most obliquely inclined from the charge).

To gain more fundamental insight into the source and consequences of the high specific impulse at the panel edges, Fig. 21 shows time resolved results for mid-line panel deflection at the grips and the position of the sand particles. It can be seen that the initially transverse motion of the sand particles, Fig. 21(b) transitions upwards upon reflection at the grips (Fig. 21(b) and (c)). The consequence of balancing momentum applied to the sandwich panel is a downward deflection (or shearing) of the face sheets which add to the stretching deformations induced by macroscopic panel bending. Fracture is simulated to occur in the weaker weld material just to the side of the vertical rib-supported region and this is consistent with the location and mode of failure seen in the experimental result shown in Figs. 21(e) and 12(c).

We have determined the specific impulse at the panel center; half-way to the panel edge; and at the panel edge, for each of the stand-off distances investigated (Fig. 22). The radial decay in impulse from the panel center is evident in these results (by comparing the impulses at positions 1 and 2). The sharp rise in impulse at the panel edge is also clearly predicted and significantly exceeds that at the panel center. However, the highest intensity impulse is discovered to (counter-intuitively) occur at the panel corner. Close examination of Fig. 17(d) and (e) shows the presence of "dimples" in the panel corners and these were also present in the panels experimentally tested at the closest stand-offs. A photograph of such a dimple is shown in Fig. 23(a) and the simulation result in Fig. 23(b).

A schematic illustration (Fig. 24), can be used to help explain how dimpling occurs. Sand that impacts the panel surface is reflected in the plane of the panel and eventually impacts the picture frame clamping. The sand that makes oblique impact with the picture frame grips is redirected towards the corner of the picture and combines with sand that was directly (non- reflectively) propagated in this direction. A strong sand reflection in the upward direction then occurs creating a specific impulse in the corner that is almost twice that at the panel center.

The schematic diagram in Fig. 24 also rationalizes why locally increased "streaks" of specific impulse extending in the extrusion direction were seen at the panel center. These arose from a local FSI effect in association with rapid bending of the face sheet between nodes formed by the (inertia stiffened) web trusses and the face sheet. This caused a locally strong upwards reflection of the sand and increased momentum into the face sheet surface. Fig. 12(b) shows the central section of the most intensely loaded panel. Significant web buckling and inter-node face sheet bending/stretching is evident with cracks in the face sheet present in regions of high local tensile strain. Fig. 25 shows the predicted damage parameter for this center region of the panel at a stand-off distance of $15 \mathrm{~cm}$. It can be seen that the front face deflection occurs very rapidly and within $0.1-0.2 \mathrm{~ms}$, and that the damage parameter in the region of observed fracture has reached a level commensurate with fracture initiation. Note that failure occurs in the panel by element erosion when the damage parameter $D=W / W_{c r}$ equals unity (see Section 3.3). 

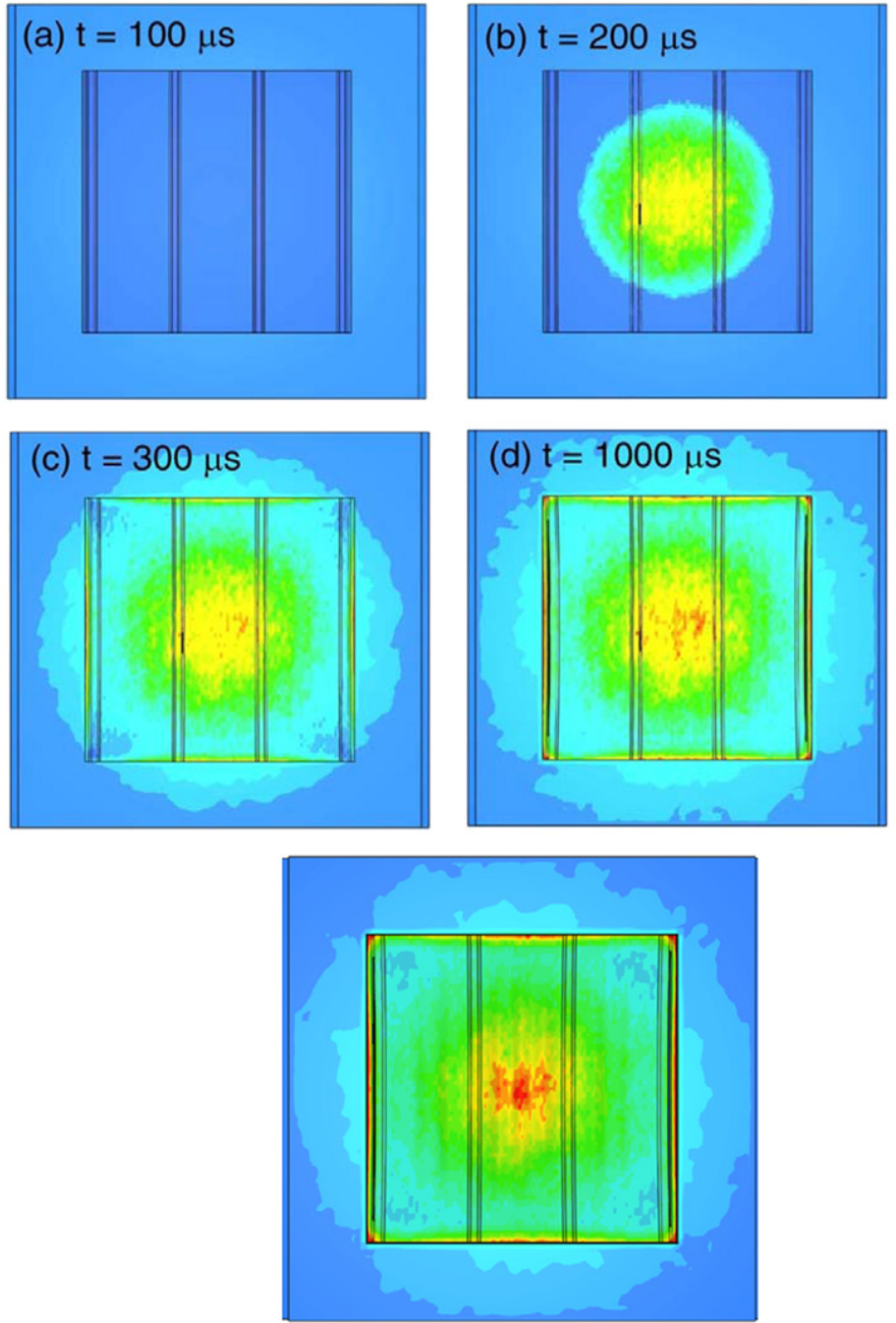

Refined $19 \mathrm{~cm}$ case with 2,000,000 soil particles and 400,000 HE particles
Impulse intensity (Pa.s)

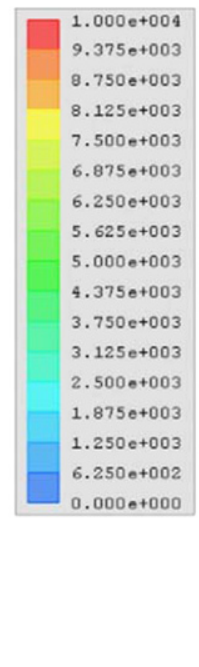

Fig. 20. Spatial distribution of the impulse intensity distribution for sand impact at the $19 \mathrm{~cm}$ stand-off distance: (a) $t=100 \mu \mathrm{s}$, (b) $200 \mu \mathrm{s}$, (c) $300 \mu \mathrm{s}$, and (d) $1000 \mu \mathrm{s}$. Note the development of "extra" impulse at the panel boundaries, the panel corners and the longitudinal streaking in the corrugation direction near the panel center.

\section{A discussion on fluid-structure interaction (FSI) effects}

Rimoli et al. (2011) performed "decoupled" calculations of the response of the aluminum sandwich panels subjected to dynamic loading by wet sand. Unlike the calculations reported here, they estimated the pressure versus time history that was imposed on the panels from the pressure exerted by the sand upon a rigid plate using the inertial hypothesis proposed by Deshpande et al. (2009). The accuracy of this decoupled approach has recently been investigated by Liu et al. (submitted for publication) for sand loading of foam-core sandwich panels. Using a coupled discrete/continuum analysis (similar to that employed here), Liu et al. (submitted for publication) have demonstrated that the loading on foam core sandwich plates is primarily inertial with only small FSI effects, i.e. decoupled calculations suffice in predicting the deflection response of foam core panels subjected to dynamic sand loading.

However, some important discrepancies emerged between predictions and observations of the deflected profiles of the corrugated core aluminum sandwich panels analyzed by Rimoli et al. (2011). Notably, the decoupled simulations were unable to capture the local bending of the front face sheet between the corrugations (see Fig. 12). This effect is accurately captured by the current coupled simulations (see Figs. 17 and 25). We attribute this to local FSI effects that emerge in the presence of discrete lattice cores, viz. the pressure exerted by the sand results in local bending of the front face sheet between the corrugations which in turn results in a reflection of the incoming sand giving an increase in the local pressure and transferred momentum. 

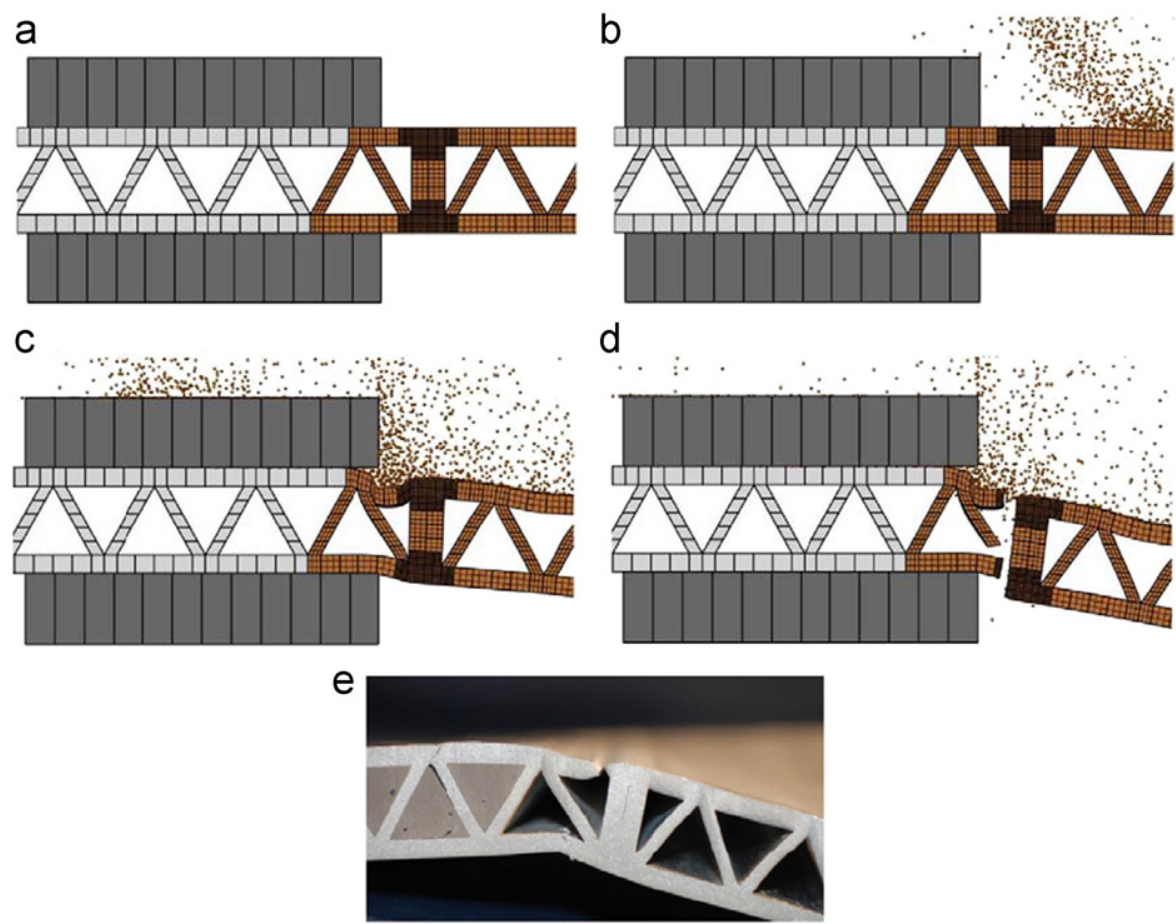

Fig. 21. Time lapse images of the simulated interaction of sand particles with the edge of a sandwich panel test structure tested at a stand-off distance of $19 \mathrm{~cm}$ : (a) $t=0 \mu \mathrm{s}$, (b) $180 \mu \mathrm{s}$, (c) $260 \mu \mathrm{s}$ and (d) $380 \mu \mathrm{s}$. Soil particles that impacted the plate were reflected in the plane of the panel and then reflected vertically at the clamped boundary. The vertical reflection imposed an additional "out of plane" impulse upon the panel and contributed to a shear-off failure at the boundaries of the panel. (e) A photograph of the region modeled after impulsive loading. The HAZ is denoted by darker element shading.

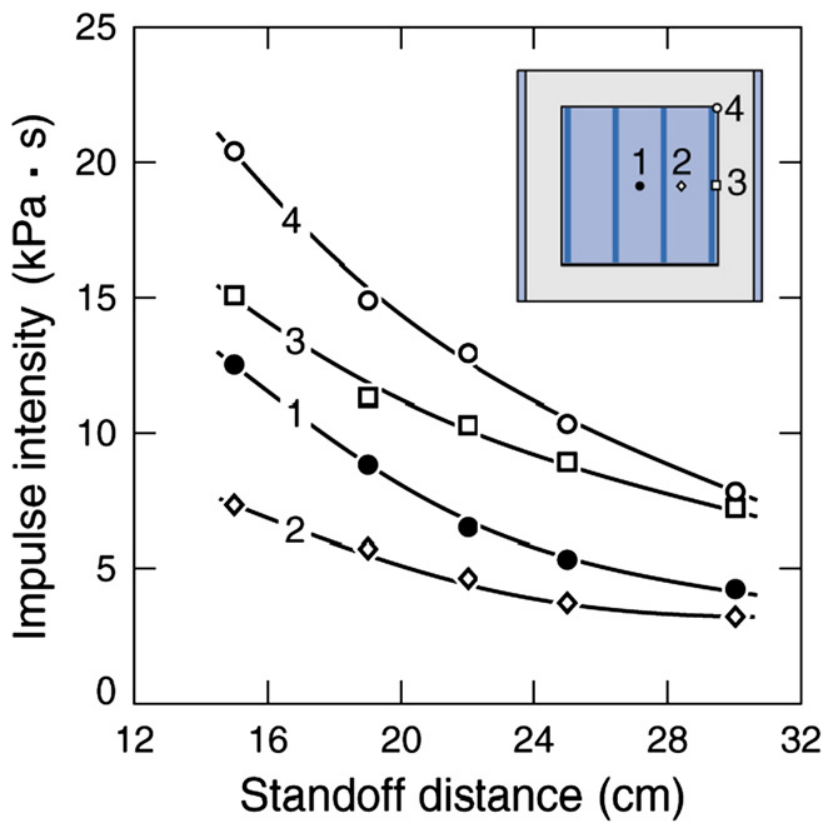

Fig. 22. Impulse intensity variation with panel location versus stand-off distance. The impulse at the panel edges (location 3 ) and corners (location 4 ) was significantly greater than that at the panel center.

To quantify this effect we have calculated the pressure-time waveforms at two locations (I and II) shown in Fig. 26(a) for the solid plates and a sandwich panel. Note that for the sandwich panel, monitor location I is mid-way between a pair of nodes while location II was aligned with the center of a core-face sheet node (a hard point). We plot in Fig. 26(b) the pressure exerted by the sand at monitor location I for the solid plate as a function of stand-off distance and show the 

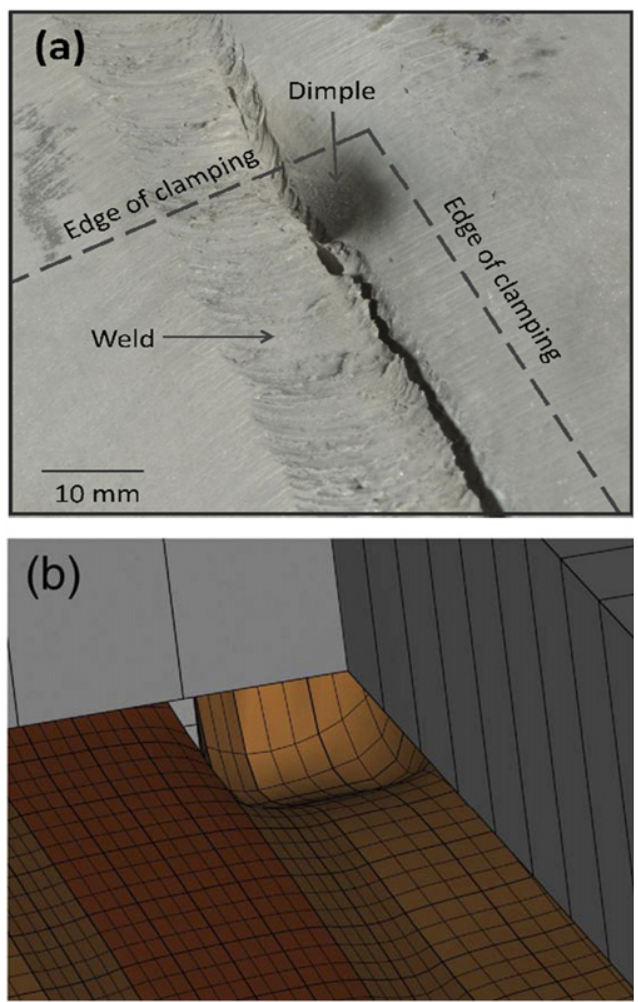

Fig. 23. Example of a dimple at one of the corners of a sandwich panel tested at a $15 \mathrm{~cm}$ stand-off: (a) experimental observation and (b) simulation result.

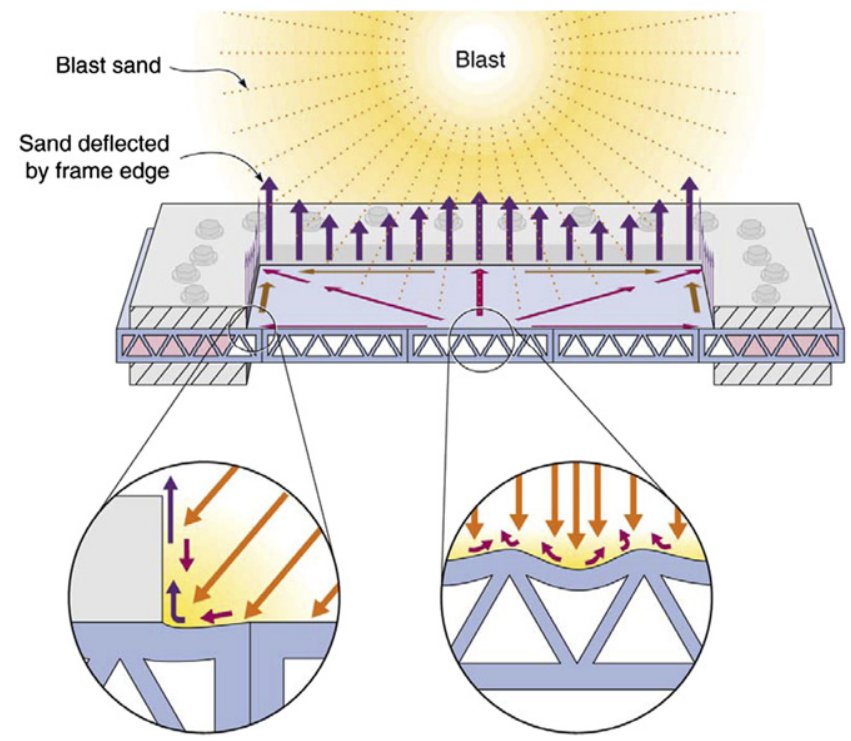

Fig. 24. Schematic illustration of the sand particle flow after impact with a sandwich panel. The clamping system and local dynamic deflections of the panel change the sand-structure interaction and the impulse intensity.

decrease in peak pressure with distance due to stretching of the sand shell. We also compare the solid plate and sandwich panel pressures recorded at location I for the $15 \mathrm{~cm}$ stand-off. It can be seen that the peak pressure applied to the sandwich panel front face was much less than that applied to the solid plate. This resulted from local bending of the front face allowing it to move away from the sand front and reducing the sand reflection intensity. Eventually, this local motion ceased and the pressure increased and remained above that of the solid plate for about $150 \mu$ s. This "extra pressure" corresponded to arrival of the tail of the sand shell which suffered a stronger reflection due to the locally concave shape of 

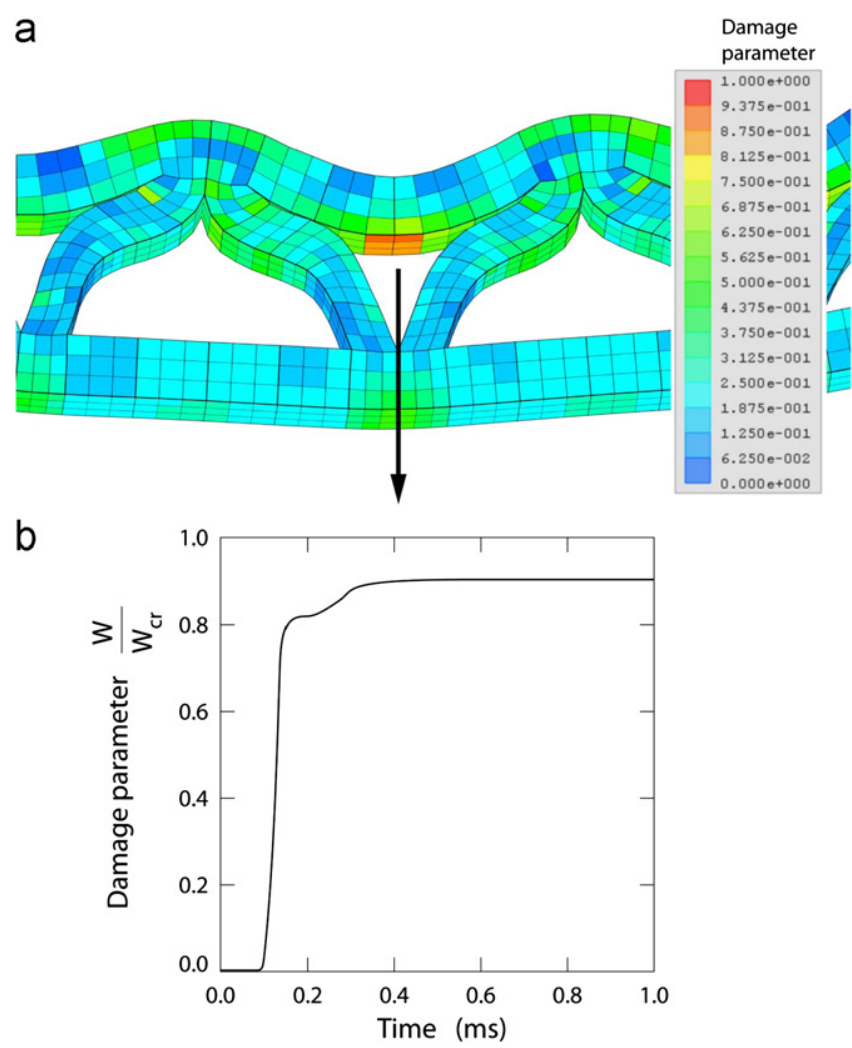

Fig. 25. (a) Simulated deformation and (b) predicted damage parameter evolution for a central region of the sandwich panel tested at a stand-off distance of $15 \mathrm{~cm}$.

the panel surface. Confirmation of this is found by comparing the pressure waveforms measured at monitor location II where no local concavity of the surface occurred (Fig. 26(c)). The pressures waveforms at this location were about the same for the plate and panel. It is evident that the pressure exerted by the sand is significantly higher on the sandwich panel during the late arriving sand impact due to the local interaction effects illustrated in Fig. 24. These pressure enhancement effects are not present in the monolithic plates or the foam core sandwich panels analyzed by Liu et al. (submitted for publication) wherein local bending of the front face sheet is precluded by the continuum foam core. We thus conclude that while on a global panel scale FSI effects in dynamic sand loading are small, these effects become significant at the local level in sandwich panels with lattice cores with cell sizes that are on the order of the core thickness.

\section{Concluding remarks}

Square edge-clamped monolithic plates and friction stir welded extruded panels both made from an AA6061-T6 alloy were subjected to localized impulse loading by the impact of explosively accelerated water saturated sand shells (Fig. 9). The impulsive load applied by the sand impact was gradually increased by reducing the stand-off distance between the test charge and panel surface. The maximum back face sheet deflection was found to be lower for the sandwich panels than for the equivalent plate in most tests. During loading the sandwich panels suffered global bending and localized core crushing and stretching. As the pressure applied by the sand increased, face sheet fracture occurred at the two clamped edges of the panels that were parallel with the corrugation and weld direction. These edge failures occurred by a combination of tensile stretching and shear-off and they always originated, and remained within the heat affected zone of the longitudinal welds. For the most intensively loaded panels additional cracks occurred at all four clamped boundaries and in the center of the panel. Some of the cracks were located within the HAZ region near welds. In contrast cracking only occurred at the edges of the monolithic plates.

A material test program was conducted to characterize the material properties of the aluminum sandwich panels and solid plates. The stress-strain curves for the base materials of the panel exhibit considerable scatter as shown in Fig. 7(a). The scatter in flow stress corresponds well with the scatter seen in the micro-hardness tests reported in Fig. 2 . The variations in flow stress and ductility are a result of the complex grain structure of the panel material shown in Fig. 2 . This grain structure resulted from the very large plastic strains and plastic strain variations induced during the extrusion process used to make the panels. These variations are not accounted for in the numerical simulations. This may be justified by the significant reduction of the strength and ductility observed in the HAZs in the vicinity of the welds (Fig. 4). 
a
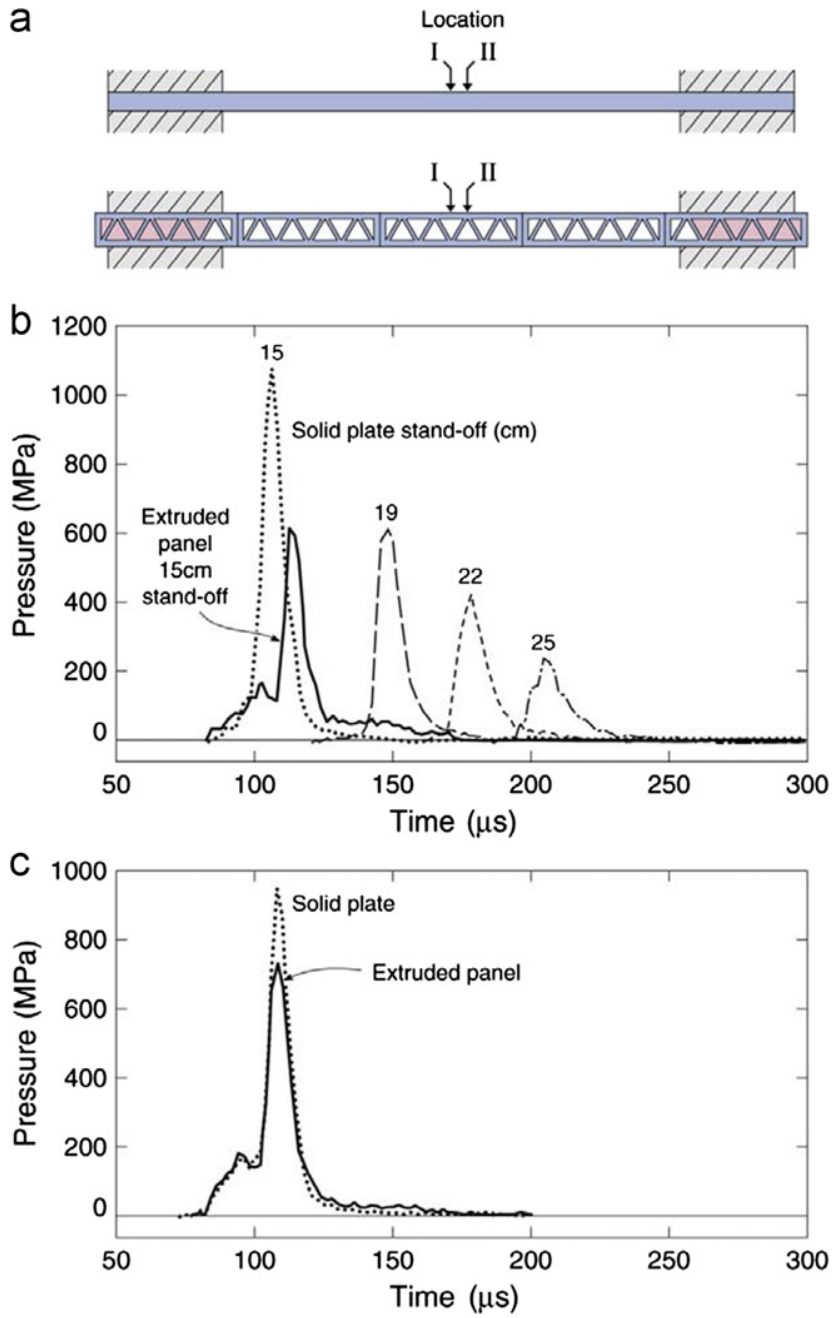

Fig. 26. Simulated pressure as a function of time exerted by the sand on the front face of the solid plate and sandwich panel at various stand-off distances: (a) the pressure at monitor locations (I and II), (b) the pressure measured at location I (the panel mid-span location) for the solid plate at various stand-off distances and the extruded panel tested at a stand-off of $15 \mathrm{~cm}$ and (c) the pressure at monitor location II for the solid plate and sandwich panel.

The fracture behavior of the panels is completely dominated by the behavior of the material in these zones (Fig. 7b), since the strains localize in these areas at rather low deformation levels. It follows that it is very important to characterize the material behavior in the HAZs and to account for this behavior in the finite element simulations via the constitutive model and fracture criterion. We find that when account of the reduced HAZ material strength is introduced in the simulations, strong strain localization occurs in the HAZs and is the precursor to panel failure. If this localization is accurately captured in the FE model, a rather simple fracture criterion may be adopted to describe material failure.

A discrete particle-based method that works with rigid, spherical, particles that transfer forces between each other through contact and collision was used to simulate the interaction between the high explosive detonation products, the soil and the aluminum panel (Fig. 14). The numerical approach was validated in a previous study, and the same blast test set-up and models of the high explosive and saturated soil were used in this study. The aluminum panels were modeled using a modified Johnson-Cook constitutive relation with Voce hardening and the Cockcroft-Latham failure criterion. The simulations show, without changing the model input for the high explosive and the soil model from previous studies, that the central displacement of the panel and the global failure were well predicted at all stand-off distances, but the failure due to local bending of the plate skin front face was not equally well captured. Thus, the material seems to behave somewhat too ductile in some of the simulations. Panel failure at the four clamped edges and in the center at the highest pressure was however well predicted (Fig. 17). The overall conclusion is that the numerical model is able to describe the structural response of the aluminum panel under blast loading with good accuracy taking the complexity of the problem and the simplicity of the numerical approach into account. 
The numerical simulations have allowed a detailed analysis of the fluid-structure interactions that occur during wet sand loading of deformable structures. They reveal the existence of strong coupling between the reflection direction of the sand and the dynamically evolving shape of the test structure. In particular, they reveal the existence of instability when an initially flat surface supported by coarsely separated nodes is impacted by a stretching sand shell. Local deformation of the structure between the nodes results in increased sand reflection normal to the original plane of the plate. This increases the impulse transferred to that region which in turn increases the concavity of the surface and the impulse transferred. The simulations have therefore revealed the existence of a sometimes strong dynamic FSI effect during wet sand loading of a structure. Analogous phenomena are activated at protuberances (such as at grips) on the plate surface. The control of these phenomena by panel design may lead to significant improvements in the performance of protective structures.

\section{Acknowledgments}

The financial support of this work by the US Office of Naval Research (ONR Grant no. N00014-07-1-0764) and the Structural Impact Laboratory (SIMLab), Centre for Research-based Innovation (CRI) at the Norwegian University of Science and Technology (NTNU) is gratefully acknowledged. The experiments were conducted at the Force Protection Industries Explosives Test Range (Edgefield, South Carolina) and we are grateful to Vernon Joynt and Keith Williams for their advice and assistance. The IMPETUS Afea Solver has been developed with financial support from The Competence Development Fund of Southern Norway, SR-Bank Næringsutvikling and Innovation Norway. The authors are also grateful to Dr. Ketill Pedersen at SINTEF Materials and Chemistry for assistance with the metallurgical investigations.

\section{References}

Allen, H.G., 1969. In: Analysis and Design of Structural Sandwich PanelsPergamon Press, Oxford.

Baibuz, V.F., Zitserman, V.Y., Golubushkin, L.M., Malyshev, I.G., 1986. The covolume and equation of state of high-temperature real gases. J. Eng. Phys. Thermo-Phys. 51, 955-956.

Børvik, T., Hopperstad, O.S., Berstad, T., Langseth, M., 2001. A computational model of viscoplasticity and ductile damage for impact and penetration. Eur. J. Mech.-A/Solids 5, 685-712.

Børvik, T., Hanssen, A.G., Dey, S., Langberg, H., Langseth, M., 2008a. On the ballistic and blast load response of a $20 \mathrm{ft}$ ISO container protected with aluminium panels filled with a local mass-Phase I: Design of protective system. Eng. Struct. 30, 1605-1620.

Børvik, T., Burbach, A., Langberg, H., Langseth, M., 2008b. On the ballistic and blast load response of a $20 \mathrm{ft}$ ISO container protected with aluminium panels filled with a local mass-Phase II: Validation of protective system. Eng. Struct. 30, 1621-1631.

Børvik, T., Hanssen, A.G., Langseth, M., Olovsson, L., 2009. Finite element engineering approaches to planar blast loading and response of structures. Comput. Struct. 87, 507-520.

Børvik, T., Olovsson, L., Hanssen, A.G., Dharmasena, K., Hansson, H., Wadley, H.N.G., 2011. A discrete particle approach to simulate the combined effect of blast and sand impact loading of steel plates. J. Mech. Phys. Solids 59, 940-958.

Clausius, R., 1880. Ueber das verhalten der kohlensaüre in bezug auf druck, volumen und temperatur. Ann. Phys. Chem. 3, $337-357$.

Cockcroft, M.G., Latham, D.J., 1968. Ductility and workability of metals. J. Inst. Met. 96, 33-39.

Deshpande, V.S., McMeeking, R.M., Wadley, H.N.G., Evans, A.G., 2009. Constitutive model for predicting dynamic interactions between soil ejecta and structural panels. J. Mech. Phys. Solids 57, 1139-1164.

Dey, S., Børvik, T., Hopperstad, O.S., Langseth, M., 2006. On the influence of fracture criterion in projectile impact of steel plates. Comput. Mater. Sci. 38 $176-191$.

Dharmasena, K.P., Wadley, H.N.G., Xue, Z., Hutchinson, J.W., 2008. Mechanical response of metallic honeycomb sandwich panel structures to high intensity dynamic loading. Int. J. Impact Eng. 35, 1102-1114.

Dharmasena, K.P., Queheillalt, D.T., Wadley, H.N.G., Chen, Y., Dudt, P., Knight, D., Wei, Z., Evans, A.G., 2009. Dynamic response of a multilayer prismatic structure to impulsive loads incident from water. Int. J. Impact Eng. 36, 632-643.

Dharmasena, K.P., Queheillalt, D.T., Wadley, H.N.G., Dudt, P., Chen, Y., Knight, D., Evans, A.G., Deshpande, V.S., 2010. Dynamic compression of metallic sandwich structures during planar impulsive loading in water. Eur. J. Mech. A/Solids 29, 56-67.

Dharmasena, K.P., Wadley, H.N.G., Williams, K., Xue, Z., Hutchinson, J.W., 2011. Response of metallic pyramidal lattice core sandwich panels to high intensity impulsive loading in air. Int. J. Impact Eng. 38, 275-289.

Elzey, D.M., Wadley, H.N.G., 2001. The limits of solid state foaming. Acta Mater. 49, 849-859.

Fleck, N.A., Deshpande, V.S., 2004. The resistance of clamped sandwich beams to shock loading. J. Appl. Mech. 71, $386-401$.

Gibson, L.J., Ashby, M.F., 1997. Cellular Solid, Structure and PropertiesCambridge University Press, Cambridge.

Hutchinson, J.W., Xue, Z., 2005. Metal sandwich plates optimized for pressure impulses. Int. J. Mech. Sci. 47, 545-569.

Johnson, G.R., Cook, W.H., 1983. A constitutive model and data for metals subjected to large strains, high strain rates and high temperatures. In: Seventh International Symposium on Ballistics, The Netherlands: The Hague, pp. 1-7.

Kambouchev, N., Noels, L., Radovitzky, R., 2006. Compressibility effects on fluid structure interactions and their implications on the blast loading of structures. J. Appl. Phys. 100, 063519.

Kambouchev, N., Noels, L., Radovitzky, R., 2007. Fluid-structure interaction effects in the loading of free-standing plates by uniform shocks. J. Appl. Mech. 74, 1042-1045.

Kane, A., Børvik, T., Berstad, T., Benallal, A., Hopperstad, O.S., 2011. Failure criteria with unilateral conditions for simulations of plate perforation. Eur. J. Mech.-A/Solids 30, 468-476.

Kooistra, G.W., Deshpande, V.S., Wadley, H.N.G., 2004. Compressive behavior of age hardenable tetrahedral lattice truss structures made from aluminum. Acta Mater. 52, 4229-4237.

Kooistra, G.W., Queheillalt, D.T., Wadley, H.N.G., 2008. Shear behavior of aluminum lattice truss sandwich panel structures. Mater. Sci. Eng. A 472 , $242-250$.

Liang, Y., Spuskanyuk, A.V., Flores, S.E., Hayhurst, D.R., Hutchinson, J.W., McMeeking, R.M., Evans, A.G., 2007. The response of metallic sandwich panels to water blast. J. Appl. Mech. 74, 81-99.

Liu, T., Fleck, N.A., Deshpande, V.S., Wadley, H.N.G. The impact of sand slugs against beams and plates: coupled discrete/continuum calculations. J. Mech. Phys. Solids, submitted for publication.

Maxwell, J.C., 1860. Illustrations of the dynamical theory of gases. Philos. Mag. 19, 19-32. 
Mills, N., 2007. In: Polymer Foams HandbookElsevier

Moongkhamklang, P., Wadley, H.N.G., 2010. Titanium alloy lattice structures with millimeter scale cell sizes. Adv. Eng. Mater. 12, 1111-1116.

Nashon, K., Hutchinson, J.W., 2008. Modifications of the Gurson model for shear failure. Eur. J. Mech. A/Solids 27, 1-17.

Olovsson, L., Hanssen, A.G., Børvik, T., Langseth, M., 2010. A particle-based approach to close-range blast loads. Eur. J. Mech.-A/Solids 29, 1-6.

Pingle, S.M., Fleck, N.A., Wadley, H.N.G., Deshpande, V.S. 2012. Discrete element calculations of the impact of a sand column against rigid structures. Int. J. Impact Eng. 45, 74-89.

Queheillalt, D.T., Wadley, H.N.G., 2009. Titanium alloy lattice truss structures. Mater. Des. 30, 1966-1975.

Queheillalt, D.T., Choi, B.W., Wadley, H.N.G., Schwartz, D.S., 2000. Creep expansion of porous Ti-6Al-4V sandwich structures. Met. Trans. A 31 A, $261-273$.

Queheillalt, D.T., Murty, Y., Wadley, H.N.G., 2008. Mechanical properties of an extruded pyramidal lattice truss sandwich structure. Scr. Mater. 95, 76-79.

Rimoli, J.J., Talamini, B., Wetzel, J.J., Dharmasena, K.P., Radovitzky, R., Wadley, H.N.G., 2011. Wet-sand impulse loading of metallic plates and corrugated core sandwich panels. Int. J. Impact Eng. 38, 837-848.

Souers, P.C., Wu, B., Haselman Jr., L.C., 1996. Detonation Equation of State at LLNL, 1995. Report UCRL-ID119262 Rev 3. Energetic Materials Center, Lawrence Livermore National Laboratory, Livermore.

Taylor, G.I., 1963. The Pressure and Impulse of Submarine Explosion Waves on Plates. The Scientific Papers of G.I. Taylor, III. Cambridge University Press, Cambridge, pp. 287-303.

Tilbrook, M.T., Deshpande, V.S., Fleck, N.A., 2006. The impulsive response of sandwich beams: analytical and numerical investigation of regimes of behaviour. J. Mech. Phys. Solids 54, 2242-2280.

Vaziri, A., Hutchinson, J.W., 2007. Metallic sandwich plates subject to intense air shocks. Int. J. Solids Struct. 44, 2021-2035.

Wadley, H.N.G., 2008. Multifunctional periodic cellular metals. Philos. Trans. R. Soc. A 364 (1838), 31-68.

Wei, Z., Deshpande, V.S., Evans, A.G., Dharmasena, K.P., Queheillalt, D.T., Wadley, H.N.G., Murty, Y., Elzey, R.K., Dudt, P., Chen, Y., Knight, D., Kiddy, K., 2008. The resistance of metallic plates to localized impulse. J. Mech. Phys. Solids 56, 2074-2091.

Wetzel, J.J.,2009. Corrugated AA6061 Impulse Response. M.S. Thesis, p. 59.

Xue, Z., Hutchinson, J.W., 2004. A comparative study of impulse-resistant metallic sandwich plates. Int. J. Impact Eng. 30, $1283-1305$. 